\title{
Genetic and functional diversity of Pseudomonas aeruginosa lipopolysaccharide
}

\section{Joseph S. Lam*, Véronique L. Taylor, Salim T. Islam, Youai Hao and Dana Kocíncová}

Department of Molecular and Cellular Biology, University of Guelph, Guelph, ON, Canada

\section{Edited by:}

Dara Frank, Medical College of

Wisconsin, USA

\section{Reviewed by:}

Robert Munson, Research Institute at Nationwide Children's Hospital, USA

Dennis Ohman, Virginia

Commonwealth University Medical

Center, USA

\section{${ }^{*}$ Correspondence:}

Joseph S. Lam, Department of

Molecular and Cellular Biology, 50

Stone Road E., Guelph, ON, Canada

N1G 2W1.

e-mail: jlam@uoguelph.ca
Lipopolysccharide (LPS) is an integral component of the Pseudomonas aeruginosa cell envelope, occupying the outer leaflet of the outer membrane in this Gram-negative opportunistic pathogen. It is important for bacterium-host interactions and has been shown to be a major virulence factor for this organism. Structurally, P. aeruginosa LPS is composed of three domains, namely, lipid A, core oligosaccharide, and the distal $\mathrm{O}$ antigen (O-Ag). Most $P$. aeruginosa strains produce two distinct forms of $\mathrm{O}-\mathrm{Ag}$, one a homopolymer of D-rhamnose that is a common polysaccharide antigen (CPA, formerly termed A band), and the other a heteropolymer of three to five distinct (and often unique dideoxy) sugars in its repeat units, known as O-specific antigen (OSA, formerly termed $\mathrm{B}$ band). Compositional differences in the $\mathrm{O}$ units among the OSA from different strains form the basis of the International Antigenic Typing Scheme for classification via serotyping of different strains of $P$. aeruginosa. The focus of this review is to provide state-of-the-art knowledge on the genetic and resultant functional diversity of LPS produced by P. aeruginosa. The underlying factors contributing to this diversity will be thoroughly discussed and presented in the context of its contributions to host-pathogen interactions and the control/prevention of infection.

Keywords: lipopolysaccharide, serotyping, biosynthesis, motility, virulence, seroconversion, bacteriophage, nucleotide sugars

\section{INTRODUCTION AND HISTORICAL PERSPECTIVES}

To classify the differences among Pseudomonas aeruginosa strains isolated from environmental or clinical settings, serological methods have been employed whereby polyclonal antisera were raised against representative strains, then cross-adsorbed with other $P$. aeruginosa strains in order to yield a collection of strain-specific antisera. In order to exploit the specificity of the antibodies within these antisera, a number of immunochemical techniques were employed including slide agglutination tests and gel-diffusion precipitation reactions. The former constitutes a rather simple method of visualizing clumping of bacteria on a microscope slide by a small aliquot of specific antiserum in a matter of seconds, while the latter allows the diffusion of antibodies and antigen, usually bacterial cell lysates, from adjacent sample wells in agarose gels until equivalent amounts of these reagents meet to form visible precipitins (Mutharia and Lam, 2007). Interestingly, the precipitin reactions also provide the resolution to distinguish between cross-reacting groups, thereby giving rise to subgrouping among a specific serotype, for instance, serogroups $2 \mathrm{a} 2 \mathrm{~b}, 2 \mathrm{a} 2 \mathrm{c}$, etc. (Stanislavsky and Lam, 1997). Though tedious, these serotyping methods were the gold standards approximately 30 years ago, and are still being used by certain public health laboratories due to the low cost and rapidity in obtaining results. Since various laboratories from different parts of the world prepare their own antisera, many $P$. aeruginosa serotyping schemes have been established, such as the Homma, Habs, Lanyi and Bergan, and Fisher Immunotyping systems (reviewed in Stanislavsky and Lam, 1997). In order to standardize results stemming from the different serotyping systems, Liu et al. (1983) coordinated a special meeting between the P. aeruginosa serotyping experts, with the initiative giving rise to a standardized serotype classification termed the International Antigenic Typing Scheme
(IATS), which has 17 serotypes based on Habs serotypes 1-12 plus 5 more serotypes from other serotyping systems (Stanislavsky and Lam, 1997). A subsequent study added 3 more serotypes to bring the total to 20 (Liu and Wang, 1990). Note that from this point onward in this review, the serotypes of $P$. aeruginosa strains mentioned are based on the IATS classification. Although it has been known that variations in the cell-surface lipopolysaccharide (LPS) of P. aeruginosa are responsible for serotyping, knowledge of the chemical structures of LPS and the underlying genetics of the biosynthetic process was lacking and prompted new research interests in this area.

The IATS serotyping scheme has been generally effective for classifying $P$. aeruginosa strains that are wildtype organisms producing smooth LPS possessing three distinct domains, namely, lipid A, core oligosaccharide (OS), and $O$ polysaccharides or $\mathrm{O}$ antigens (O-Ag). This is not often the case in clinical settings as many of these isolates are found to be either partially lacking or completely devoid of O-Ag. Serotyping of chronic bacterial isolates from cystic fibrosis (CF) patients for epidemiological studies was particularly problematic because a very high proportion of these bacteria were found to be either polytypeable by more than one serotyping antisera or non-typable (NT). This has prompted the generation of new typing reagents based on monoclonal antibodies (mAbs) specific against each of the original 17 IATS serotypes (Lam et al., 1987a,b). In ensuing studies, comparison of the P. aeruginosa typing efficiencies with the complete set of anti-O1 to anti-O17 mAbs versus other methods, such as phage-susceptibility typing, pyocin typing, and restriction fragment length polymorphism (RFLP) DNA fingerprinting was performed (Ojeniyi et al., 1989, 1990; Speert et al., 1994); these methods differed substantially in their capacity to indentify unique typing patterns. Although RFLP was deemed to have the greatest discrimination power, LPS-based serotyping appears 
preferable for other indications because it is the simplest to perform. The use of mAb typing reagents was found to be more specific and accurate than the use of polyclonal antibody typing kits in assigning a specific serotype designation to many of the polytypeable P. aeruginosa isolates (Dasgupta et al., 1994). However, to classify strains that have been determined as NT by serotyping, other methods are required, for instance, the use of molecular techniques (discussed below as a consequence of sequencing results of all 20 IATS O-Ag biosynthesis gene clusters). This provided the rationale for investigating LPS biosynthesis and its assembly using genetic and biochemical approaches.

\section{GENETICS OF 0-SPECIFIC ANTIGEN BIOSYNTHESIS}

Most P. aeruginosa strains produce two different forms of $\mathrm{O}-\mathrm{Ag}$, one of which contains a homopolymer of D-rhamnose, arranged in $\alpha 1 \rightarrow 3$, $\alpha 1 \rightarrow 2, \alpha 1 \rightarrow 3$ trisaccharide repeats. This homopolymeric D-rhamnan is the common polysaccharide antigen (CPA; formerly termed A band) among $P$. aeruginosa strains. More details of the properties of CPA will be discussed in later sections. The other form of O-Ag produced by $P$. aeruginosa is a heteropolymer with three to five distinct sugars in its repeat units, and is named $\mathrm{O}$-specific antigen (OSA; formerly termed $\mathrm{B}$ band). The differences of the composition of the $\mathrm{O}$ units form the basis of the IATS serotyping scheme. Knirel et al. (2006) have made a significant contribution to our understanding of all the serotypes by systematically elucidating the chemical structures of the OSA of all 20 IATS serotypes (Table 1). To appreciate the complexity and diversity of LPS produced by $P$. aeruginosa, it is noteworthy that heterogeneity exists in the chain length of either form of O-Ag present on the cell surface used to "cap" the core OS of P. aeruginosa (Figure 1). This accounts for the "ladder-banding" pattern when LPS from $P$. aeruginosa is analyzed by silver-stained SDS-PAGE gels and Western immunoblotting (Rocchetta et al., 1998a).

The importance of the OSA toward virulence and its use in serotyping has made it an attractive target for genetic studies to help understand both the plasticity of this region of the LPS and the complex steps of OSA biosynthesis. OSA biosynthesis follows the Wzy-dependent pathway model, originally proposed by Whitfield (1995); it involves the sequential activities of a series of integral inner membrane (IM) proteins, for which we have recently obtained comprehensive topological data helping to explain their respective functions (Islam et al., 2010). In this model, OSA sugar repeats are sequentially built on the lipid carrier undecaprenyl pyrophosphate (UndPP) on the cytoplasmic face of the IM. The UndPP-linked OSA repeats are then translocated to the periplasmic face of the IM by the flippase Wzx (Burrows and Lam, 1999), where they are polymerized by Wzy (De Kievit et al., 1995) through a putative catch-and-release mechanism (Islam et al., 2011), to modal lengths regulated by Wzz (Burrows et al., 1997) and

\section{Table 1 | O-Antigen repeating units which compose the 20 IATS reference strains.}

\begin{tabular}{|c|c|}
\hline IATS serotype & O-specific antigen repeat* \\
\hline $\mathrm{O} 2$ & $\rightarrow 4)$-D-ManNAc3NAmA-( $\beta 1 \rightarrow 4)$ )-L-GulNAc3NAcA-(1 $\rightarrow 3)$-D-FucNAc-( $(\beta 1 \rightarrow$ \\
\hline 016 & $\rightarrow 4)$-D-ManNAc3NAmA-( $(\beta 1 \rightarrow 4)$-D-ManNAc3NAcA-( $\beta 1 \rightarrow 3)$-D-FucNAc-( $\beta 1 \rightarrow$ \\
\hline 018 & $\rightarrow 4)$-L-GulNAc3NAmA-(1 $\rightarrow 4)$-D-ManNAc3NAcA-( $\beta 1 \rightarrow 3)$-d-FucNAc- $(1 \rightarrow$ \\
\hline $\mathrm{O} 4$ & $\rightarrow 2)$-L-Rha-(1 $\rightarrow 3$ )-L-FucNAc-(1 $\rightarrow 3$ )-L-FucNAc- $(1 \rightarrow 3)$-D-QuiNAc- $(1 \rightarrow$ \\
\hline $\mathrm{O} 6$ & $\rightarrow$ 3)-L-Rha-(1 $\rightarrow 4$ )-D-GalNAc3OAcAN-(1 $\rightarrow 4)$-D-GalNFoA-(1 $\rightarrow$ 3)-D-QuiNAc- $(1 \rightarrow$ \\
\hline $\mathrm{O} 7$ & $\rightarrow 4)$-Pse4OAc5NRHb7NFo-(2 $\rightarrow 4)$-D-Xyl-( $(\beta 1 \rightarrow 3)$-D-FucNAc- $(1 \rightarrow$ \\
\hline O8 & $\rightarrow 4)$-Pse4OAc5NAc7NFo-(2 $\rightarrow 4)$-d-Xyl-( $(\beta 1 \rightarrow 3)$-d-FucNAc- $(1 \rightarrow$ \\
\hline 011 & $\rightarrow 2)$-D-Glc- $(\beta 1 \rightarrow 3)-$-LFucNAc- $(1 \rightarrow 3)$-D-FucNAc- $(\beta 1 \rightarrow$ \\
\hline 012 & $\rightarrow$ 8)-8eLeg5NAc7NAc-(2 $\rightarrow 3$ )-L-FucNAm-(1 $\rightarrow 3)$-D-QuiNAc- $(1 \rightarrow$ \\
\hline 013 & $\rightarrow$ )-L-Rha-(1 $\rightarrow 3$ )-L-Rha-(1 $\rightarrow 4)$-D-GalNAc3OAcA-(1 $\rightarrow 3$ )-D-QuiNAc-( $\beta 1 \rightarrow$ \\
\hline 014 & $\rightarrow[$ [D-Glc-1 $\rightarrow 3)]$-L-Rha-( $1 \rightarrow 3)$-L-Rha-( $1 \rightarrow 4)$-D-GalNAc3OAcA- $(1 \rightarrow 3)$-d-QuiNAc- $(\beta 1 \rightarrow$ \\
\hline 015 & $\rightarrow 2)$-D-Ribf-( $(\beta 1 \rightarrow 4)-\mathrm{D}-$ GalNAc-( $1 \rightarrow$ \\
\hline 017 & $\rightarrow 4)$-L-Rha-(1 $\rightarrow 3)$-D-ManNAc-( $\beta 1 \rightarrow$ \\
\hline
\end{tabular}

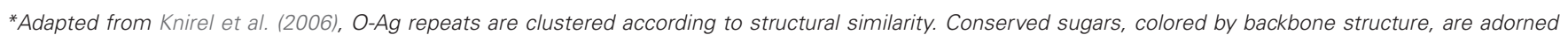

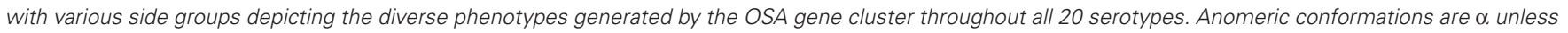

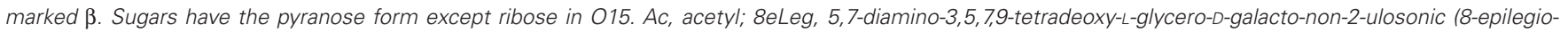

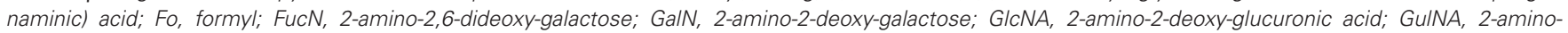

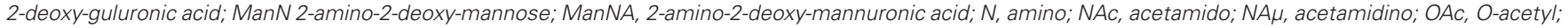

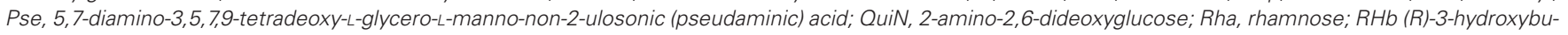
tanoyl; Rib, ribose; SHb, (S)-3-hydroxybutanoyl.

In the polymer, QuiNAc is linked to the pseudaminic acid via the 3-hydroxybutanoyl group.

* *uiNAc is linked to the pseudaminic acid via the 3-hydroxybutanoyl group. 


\section{Diversity of SuRfaCe LPS Glycoforms in A Single CelL}

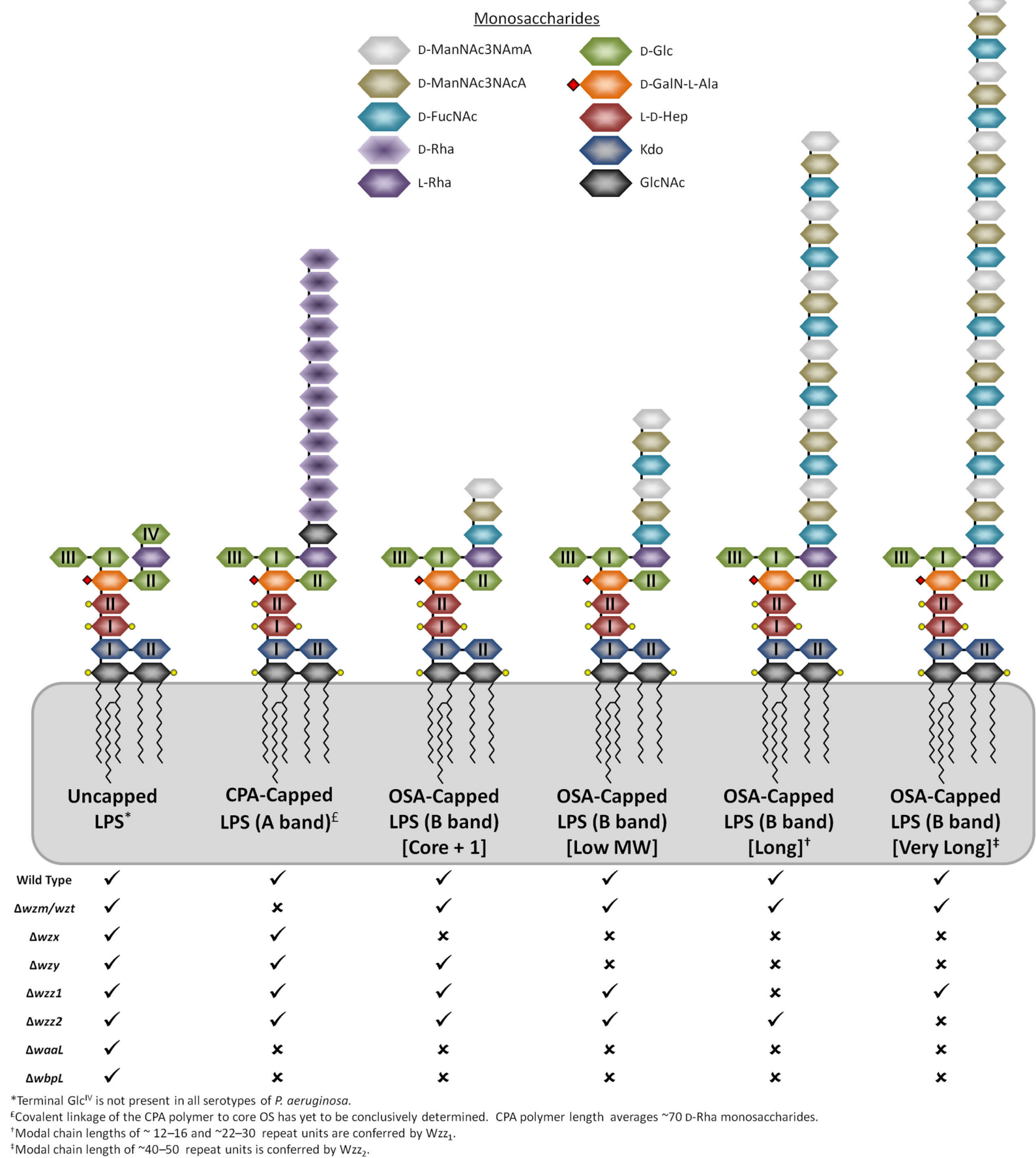

FIGURE 1 | Representations of the heterogeneity/diversity of the LPS glycoforms present on the surface of a single $P$. aeruginosa cell. Genetic defects in members of various assembly pathway genes and their resultant changes to the variety of LPS glycoforms present have been indicated, with " $\checkmark$ " or " $\mathbf{x}$ " representing their presence or absence, respectively. Substitutions of various lipid $A$ and core OS sugars with phosphate groups and L-Ala have been indicated with yellow circles and red diamonds, respectively. The OSA polymer from serotype $\mathrm{O} 5$ has been displayed as a representative polymer.
$\mathrm{Wzz}_{2}$ (Daniels et al., 2002). The modal length of OSA imparted by $\mathrm{Wzz}_{2}$ (40-50 repeat length) is longer than that imparted by $\mathrm{Wzz}_{1}$ (12-16 repeats and 22-30 repeats; Daniels et al., 2002). However, $\mathrm{Wzz}_{1}$ is apparently more important for virulence than $\mathrm{Wzz}_{2}$ (Kintz et al., 2008). Finally, the complete OSA chain is ligated to lipid A-core by the O-Ag ligase WaaL (Abeyrathne et al., 2005; Abeyrathne and Lam, 2007). Preliminary investigations mapped the OSA cluster to 37 min of the P. aeruginosa PAO1 (serotype O5) genome (Lightfoot 
and Lam, 1993), corresponding to pa3141 to pa3160 in the annotated genome of strain PAO1 (Stover et al., 2000). This first reported LPS OSA cluster was isolated from a cosmid-based genomic library. Clone pFV100 from the library was able to complement mutant ge6, a Tn5-751 insertional mutant of PAO1, defective in B band (OSA) biosynthesis (Lightfoot and Lam, 1993). Subsequently, Burrows et al. (1996) obtained the sequence of the entire OSA cluster. To characterize the function of the genes encoded in this cluster, knockout mutant constructs were generated for each of the genes and the mutants were examined for their effect on LPS production in $P$. aeruginosa. The list of OSA biosynthesis genes in this serotype O5 cluster and their functions were determined based on genetic studies as well as biochemical and chemical evidence (Figure 2A; Table 2, Burrows et al., 1996). Following the success in characterizing the O5 OSA biosynthesis locus, the sequences of the O6 (Belanger et al., 1999) and O11 (Dean et al., 1999) OSA loci were also determined. Comparisons among the newly sequenced loci revealed that all three OSA loci were flanked by himD/ihfB (pa3161) on the $5^{\prime}$ end and terminated with wbpM (pa3141) on the $3^{\prime}$ end. These observations are essential for establishing the conserved chromosomal locus for the OSA cluster, though the genes within the locus are the most varied in the P. aeruginosa genomes regardless of serotype. This information eventually allowed Raymond et al. (2002) to clone and sequence the OSA loci from all 20 IATS serotypes. Based on their sequencing data, the general genetic structures of the OSA loci of all the serotypes could be divided into 11 distinct groups based on the protein families that the genes in these loci encode, as well as the presence of insertion sequences (IS) and deletions (Figure 2B; Raymond et al., 2002). This group has also presented the sequences of a set of primers for PCR amplification of each of the IATS serotypes, meaning that a PCR-based approach can be used to correctly type clinical isolates that have previously been evaluated as NT by any typing antisera. However, thus far, there has been no systematic study conducted by any group to test the capability of using these primers for consistently typing clinical strains of $P$. aeruginosa even though the potential to do so exists. These initial genetic investigations helped to reveal differences among the OSA clusters; worth noting is the anomaly discovered regarding the entire loss of the OSA cluster in the O15 serotype. Strains that belong to this serotype were previously identified using both polyclonal antibody typing kits and mAb-based serotyping (Lam et al., 1987b). It was proposed by Raymond et al. (2002) that in serotype O15, the genes involved in its OSA biosynthesis may not necessarily be residing in the usual OSA locus as in other serotypes. Additionally, in serotype O6, the wzy gene does not reside in the OSA cluster (Belanger et al., 1999). Further, in serotype O5, the transcriptional start site for $w z x$ exists within the wzy gene, and there is a large IS at the $3^{\prime}$ end of the O5 cluster upstream of $w b p M$ (Burrows et al., 1996). This variation helps to explain the diversity of the LPS in P. aeruginosa as a property of the genetic differences among the IATS serotypes. Other factors that influence the OSA diversity are outlined in the following sections.

\section{EVIDENCE OF HORIZONTAL GENE TRANSFER REVEALS THE PRESENCE OF CONSERVED AND DUPLICATED CLUSTERS IN CERTAIN SEROTYPES}

The high conservation of the $w b p M$ gene and its localization at the $3^{\prime}$ end of the OSA loci among all 20 serotypes is not the only commonality among all of the OSA loci. A major factor in genetic reassortment

Table 2 | P. aeruginosa PAO1 serotype 05 OSA biosynthesis cluster*.

\begin{tabular}{|c|c|c|c|}
\hline Gene & Proposed/demonstrated function & $\mathbf{M o l} \% \mathbf{G}+\mathbf{C}$ & References \\
\hline$w z z / p a 3160$ & OSA chain length regulator & 49.5 & Burrows et al. (1997), Daniels et al. (2002) \\
\hline wbpA/pa3159 & UDP-N-acetyl-D-glucosamine 6-dehydrogenase & 54.5 & Miller et al. (2004) \\
\hline$w b p B / p a 3158$ & $\begin{array}{l}\text { UDP-2-acetamido-2-deoxy-D-glucuronic } \\
\text { acid 3-dehydrogenase }\end{array}$ & 52.8 & Westman et al. (2009) \\
\hline wbpC/pa3157 & Possible O-acetyltransferase & 53.1 & \\
\hline$w b p D / p a 3156$ & $\begin{array}{l}\text { UDP-2-acetamido-3-amino-2,3-dideoxy-D-glucuronic } \\
\text { acid N-acetyltransferase }\end{array}$ & 53.9 & Wenzel et al. (2005), Westman et al. (2009) \\
\hline wbpE/pa3155 & $\begin{array}{l}\text { UDP-2-acetamido-2-dideoxy-D-ribo-hex-3-uluronic } \\
\text { acid transaminase }\end{array}$ & 52.8 & Westman et al. (2009) \\
\hline wzy/pa3154 & OSA $\alpha$-polymerase & 44.6 & $\begin{array}{l}\text { De Kievit et al. (1995), Islam et al. (2010), } \\
\text { Islam et al. (2011) }\end{array}$ \\
\hline wzx/pa3153 & OSA unit flippase & 49.3 & Burrows and Lam (1999), Islam et al. (2010) \\
\hline hisH2/pa3152 & Imidazole glycerol phosphate synthase subunit & 49.3 & King et al. (2009) \\
\hline hisF2/pa3151 & Imidazole glycerol phosphate synthase subunit & 50.0 & King et al. (2009) \\
\hline$w b p G / p a 3150$ & Amidotransferase & 44.5 & \\
\hline$w b p H / p a 3149$ & Glycosyltransferase & 45.6 & \\
\hline wbpl/pa3148 & UDP-N-acetylglucosamine 2-epimerase & 50.2 & Westman et al. (2009) \\
\hline wbpJ/pa3147 & Glycosyltransferase (GT-4) & 54.5 & \\
\hline$w b p K / p a 3146$ & NAD-dependent epimerase/dehydratase & 56.8 & \\
\hline$w b p L / p a 3145$ & Glycosyltransferase & 55.5 & Rocchetta et al. (1998a) \\
\hline wbpM/pa3141 & Nucleotide sugar epimerase/dehydratase & 61.9 & Creuzenet and Lam (2001) \\
\hline
\end{tabular}

*Modified from Burrows et al. (1996), the information in this table has been updated with references which indicate that either genetic or biochemical evidence have been collected to demonstrate the function of each of these genes within the OSA biosynthesis cluster of PAO1 serotype O5. Note that in contrast to the genome of P. aeruginosa, which has a relatively high mol\% G+C content (67\%), the genes within this cluster showed significantly lower mol\% G $+C$, ranging from 45.2 to $61.9 \%$, evidence of horizontal gene transfer. 


\section{Predicted/Determined Gene Function}

$\begin{array}{ll}\square \text { Chain length determinant } & \square \text { UDP-N-acetylglucosamine 2-epimerase } \\ \square \text { Oxidoreductase family, NAD-binding Rossman fold } & \mathbf{1} \text { Glycosyltransferase } \\ \square \text { NAD-dependent epimerase/dehydratase family } & \mathbf{2} \text { Glycosyltransferase } \\ \square \text { DegT/DnrJ/EryC1/StrS family } & \mathbf{4} \text { Glycosyltransferase } \\ \square \text { Cytidylyltransferase } & \square \text { Polysaccharide biosynthesis protein } \\ \square \text { NeuB family } & \square \text { Polysaccharide biosynthesis protein } \\ \square \text { Bacterial transferase hexapeptide (four repeats) } & \square \text { Insertion sequence } \\ \square \text { UDP-Glucose/GDP-Mannose dehydrogenase family } & \end{array}$

A (1S1209

B 01 PIZ
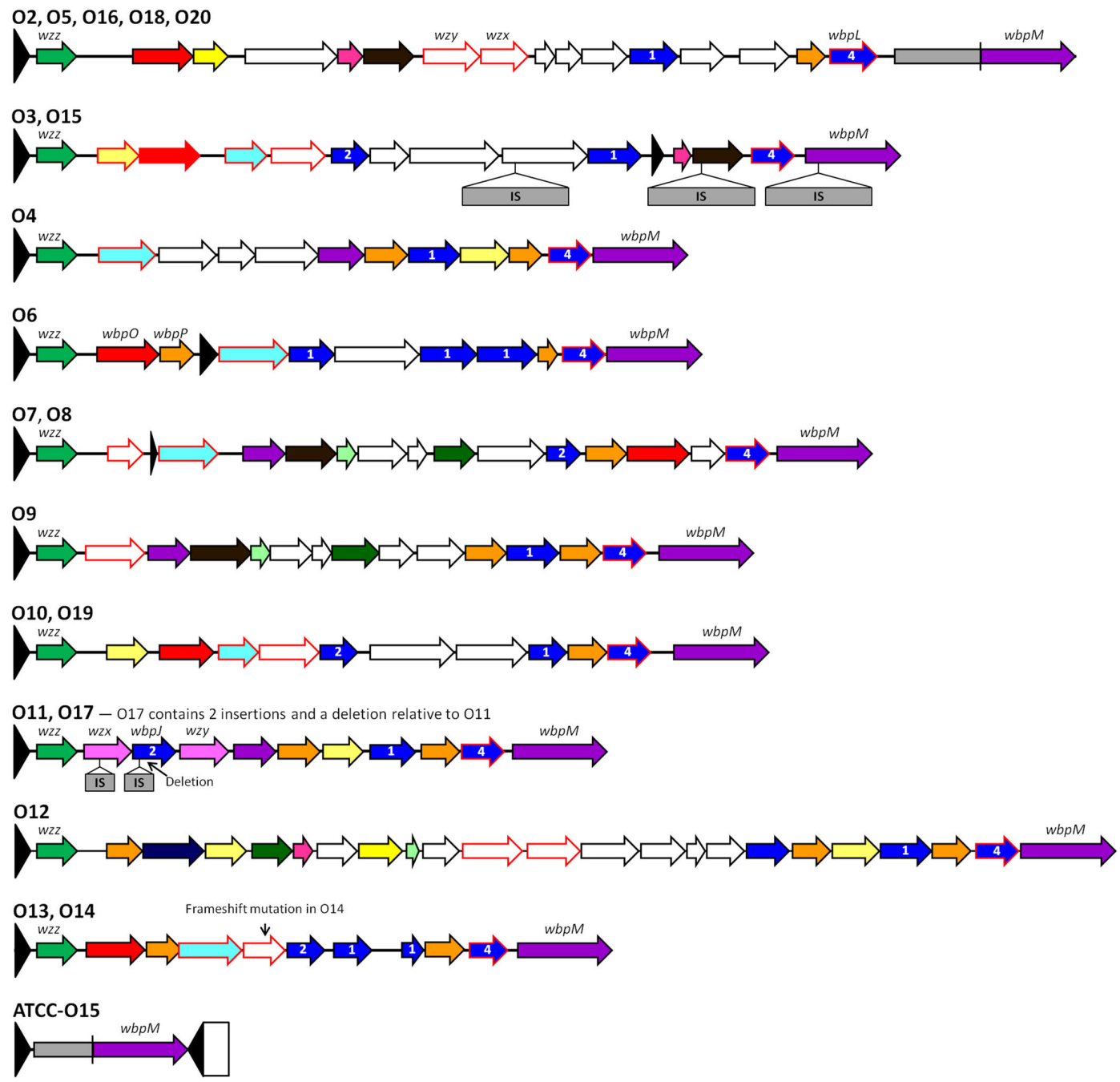

FIGURE 2 | Organization of the genes within OSA biosynthesis clusters. (A) OSA biosynthesis cluster of serotype 05 adapted from Burrows et al. (1996). The gene cluster is located on the complementary strand; genes which match the PFAM designation are colored accordingly. Genes not involved in OSA biosynthesis are depicted in gray including a large insertion sequence (IS). (B) Adapted from Raymond et al. (2002), the OSA biosynthesis gene clusters were organized into 11 groups based on sequence conservation. Genes were designated using the PFAM database; specific protein families which occur a minimum of three times throughout all 20 OSA biosynthesis clusters are represented by a specific color. A red outline depicts an ORF with potential transmembrane-spanning domains. Previously identified genes are labeled above the respected cluster if present within the serotype. Insertion sequences (IS) present within genes are depicted by a secondary gray box. 
is horizontal gene transfer (HGT), i.e., the direct transmission of genetic information across the species barrier, which often results in similar/identical gene products. Interestingly, Dean and Goldberg (2000) probed all 20 serotypes for the presence of genes that are conserved in the O11 OSA biosynthesis cluster, and discovered that the IATS O17 strain possesses a cryptic copy of the O11 locus within its genome. The $\mathrm{O} 11$ cluster was apparently rendered non-functional due to the presence of IS:SPA11B disrupting the $5^{\prime}$ end of the $w z y$ gene. However, when a complete O11 OSA cluster was supplied in trans, LPS produced by the complemented strain reacted with antiO11 antiserum in Western immunoblotting. This suggested that the cryptic O11 serotype genes found within the O17 strain were at one time functional. The presence of a secondary locus within one genome lends support to HGT. Apparently, the OSA LPS genes for the O17 serotype that were acquired or have evolved may have caused a gradual loss of function or suppression to the O11 OSA biosynthesis gene cluster through the incorporation of an IS element. Interestingly, the O17 OSA serotype is very similar to the Burkholderia cepacia serogroup $\mathrm{O} 5$ antigen, confirming that this may be an ancestral locus which was acquired by HGT (Dean and Goldberg, 2000). Similarly, Raymond et al. (2002) discovered the presence of an additional cryptic locus corresponding to the $\mathrm{O} 3$ cluster within the genome of serotype $\mathrm{O} 15$, with further investigation revealing that the $\mathrm{O} 3$ cluster in the O15 strain was rendered non-functional due to IS elements at two different sites within the cluster.

Evidence that HGT contributes to the diversity of $P$. aeruginosa LPS is not limited to transfer of the entire OSA biosynthesis locus. Varying degrees of genetic information exchange between bacteria are apparent since bacterial pathogens of different genera share conserved metabolic pathways for the biosynthesis of nucleotide sugars. A number of rare sugars are found in the OSA of $P$. aeruginosa LPS, e.g., L-FucNAc (a constituent of the O11 OSA), di$N$-acetylated mannuronic acid (D-ManNAc3NAcA, a constituent of the O5 OSA), and a uronamide sugar GalNAcAN (a constituent of O6 OSA). The metabolic pathways for the biosynthesis of the nucleotide-activated precursors for these rare sugars are only found in a few bacterial pathogens but not in humans (Kneidinger et al., 2003; Westman et al., 2008, 2009; King et al., 2010). The biosynthesis of UDP-L-FucNAc from the substrate UDP-D-GlcNAc, requires the products of three genes from the serotype O11 OSA cluster, namely, $w b j B, w b j C$, and $w b j D$. Two sets of functional homologs of these three genes are found in Staphylococcus aureus, namely cap5E-cap $5 F-c a p 5 G$ and cap8E-cap $8 F-c a p 8 G$ for the biosynthesis of serogroup- 5 and serogroup- 8 capsular polysaccharides, respectively (Kneidinger et al., 2003). The complexity of the biosynthesis of the UDP-activated precursor of D-ManNAc3NAcA requires five steps. Indeed, the activity of the encoded products of $w b p A, w b p B$, $w b p E, w b p D$, and $w b p I$, acting in this particular order, and also starting with UDP-GlcNAc as the starting substrate, have been fully characterized (Westman et al., 2008, 2009). The same pathway is shared by Bordetella pertussis as it also possesses D-ManNAc3NAcA as a sugar in its LPS. However, only four of the five genes, $w l b A$, $w l b B, w l b C, w l b D$, which are functional homologs of $w b p B, w b p E$, $w b p D$, and $w b p I$, respectively, are localized within the O-Ag biosynthesis gene clusters. Two copies of the homolog of $w b p A$ were found elsewhere in the B. pertussis genome (Westman et al., 2008). In a separate investigation, our group has determined that $w b p O$, $w b p P$, and $w b p S$ encode the enzymes for the three metabolic steps that convert UDP-GlcNAc by oxidation ( $\mathrm{WbpO}$ ), epimerization (WbpP), and amidotransfer ( $\mathrm{WbpS}$ ) to form the uronamide sugar precursor UDP-GalNAcAN for O6 OSA. Interestingly, functional homologs of these three genes were found in Escherichia coli O121. As well, homologs of these three genes were also found in Francisella tularensis (King et al., 2010); however, they have not been tested to determine whether they could complement knockout mutants of the $P$. aeruginosa genes to restore production of O6 LPS that contains GalNAcAN in its O-Ag unit. Therefore, $P$. aeruginosa and other bacterial pathogens likely acquired genes for the biosynthesis of the abovementioned UDP-sugars from common ancestors. However, investigation of the evolutionary derivations and lineages of these pathways is beyond the scope of this review.

\section{EVIDENCE OF DIVERSITY IN LPS EXPRESSION IN P. AERUGINOSA DUE TO CHROMOSOMAL INSERTIONS}

Large chromosomal inversions (LCIs), which can be induced by ISs, persist throughout Gram-negative bacteria and have altered the balance between chromosomal stability and variability. Clonal isolates taken from CF patients were found to contain additional, nonconserved LCIs (Schmidt et al., 1996). P. aeruginosa "clone C," found in various geographic locations and in non-CF patients (Kidd et al., 2011), possesses a particular additional sequence, IS6100, which was first discovered in Mycobacterium tuberculosis and known to cause genetic rearrangements in heterologous hosts. The LCIs of the "clone C" strains have been associated with wbpM (pa3141) disruption causing loss of the OSA (Kresse et al., 2003). The genomes of two CF isolates were compared to that of the wildtype PAO1, with regions of high variability localized to the OSA biosynthesis locus. Targeted sequencing of the OSA cluster provided a high-resolution view of the genetic changes that arise during clonal infection of $\mathrm{CF}$ patients. Genomes of all late-stage clinical isolates contained ISs, as judged by gel electrophoresis (Spencer et al., 2003). The OSA region of a clonal isolate (strain 1-60) was nearly identical to serotype O1 except for the presence of a large 1.5-kb IS, which disrupted a reading frame responsible for the biosynthesis of an unspecified nucleotide sugar. Additionally, a second strain (2-164) was found to contain a 2-bp deletion in $w b p Q$, which has not yet been characterized. Both of these observed mutations caused defects in LPS production and conferred a NT phenotype. Interestingly, some of the earlier NT strains did not contain the IS elements (Spencer et al., 2003). Strainspecific islands were discovered with high similarity to previously identified sequences (e.g., PAGI-1 in O-Ag biosynthesis) as well as some phage-related sequences; however, these contained a low mol\% $\mathrm{G}+\mathrm{C}$ content possibly indicating acquisition from other bacterial species (Spencer et al., 2003), since the P. aeruginosa genome has a high mol\% G + C content. Whole-genome sequencing has begun to provide snapshots of these genetic changes, which occur during clonal infection; future work using this approach may provide a roadmap for navigating the infection stages of $P$. aeruginosa.

\section{LYSOGENIC CONVERSION BY BACTERIOPHAGE ALTERS THE OSA SEROTYPE TO PROMOTE RESISTANCE}

A natural part of bacteriophage biology is engagement of a lysogenic cycle wherein a temperate phage invades a bacterial cell and incorporates its genetic material into the host genome, leading to the 
propagation of phage DNA during host cell replication. This part of the phage life cycle could also lead to the incorporation of exogenous bacterial genes into the host genome (Miller et al., 1974). The D3 phage is a temperate phage that readily infects P. aeruginosa (Cavenagh and Miller, 1986). LPS-specific phage-dependent conversion of the OSA occurs throughout Gram-negative bacteria (Robbins et al., 1965; Bagdian et al., 1966). Holloway and Cooper (1962) observed that after strain PAO1 (serotype O5) was infected with D3 phage, at least $20 \%$ of the new colonies from subcultures tested could not be agglutinated by O5-specific typing antiserum. The mechanism of the changes occurring at the bacterial cell surface was unknown at the time. In a later study, a similar observation was made by the Hancock group who showed that lysogenized PAO1 cells had an altered LPS phenotype (Hancock et al., 1983), and this change was later determined to be due to the addition of an acetyl group at position 4 of the fucosamine residue and an alteration in the linkage of the trisaccharide repeating unit bond from $\alpha 1 \rightarrow 4$ to $\beta 1 \rightarrow 4$ (Kuzio and Kropinski, 1983). In a more recent study by our group, a region of the D3 genome was found to contain a gene that hybridized in Southern blots to an $\mathrm{O}$-acetylation gene found in the PAO1 genome (Newton et al., 2001). This region spans $3.6 \mathrm{~kb}$ of the $\mathrm{D} 3$ genome, and contains three genes: (i) oac (encodes an $\mathrm{O}$-acetylase), which adds an $\mathrm{O}$-acetyl group to the OSA FucNAc residue, (ii) $w z y_{\beta}$ (encodes a $\beta$-polymerase) which polymerizes the OSA repeats to form $\beta 1 \rightarrow 4$ linkages, and (iii) iap (encodes an $\alpha$-polymerase inhibitor, a small 31 amino acid peptide with a single transmembrane domain). Iap possesses the activity to render $\mathrm{Wzy}_{\alpha}$ non-functional thereby preventing the formation of the usual $\alpha 1 \rightarrow 4$ linkage among O-Ag subunits of strain PAO1 (Newton et al., 2001). Expression of this operon in trans produced an LPS banding pattern similar to that of LPS from O16, and these bands reacted strongly with the anti-O16 mAb MF47-4 in Western immunoblotting but not with the anti-O5 mAb MF15-4 (Newton et al., 2001). O-Ag subunits of serotypes $\mathrm{O} 2$ and $\mathrm{O} 16$ are linked by $\beta 1 \rightarrow 4$ bonds, and both serotype strains contain a functional $w z y_{\alpha}$ that is actively being repressed by a previously undetected iap. Interestingly, the $w z y_{\beta}$ gene in $\mathrm{O} 2$ and $\mathrm{O} 16$ was not localized to the OSA biosynthesis cluster, further supporting the idea that this could be a D3 phage-associated gene. The authors initially suggested that $w z y_{\beta}$ and iap identified in $P$. aerugions $\mathrm{O} 2$ and $\mathrm{O} 16$ strains are xenologs of the $\mathrm{D} 3$ phage. However the $\mathrm{mol} \% \mathrm{G}+\mathrm{C}$ of $w z y_{\beta}$ and iap respectively are inconsistent when compared to the mol\% G $+\mathrm{C}$ values of both the PAO1 and the D3 phage genomes; therefore, the authors attributed the origin of these genes to an exogenous source (Kaluzny et al., 2007).

\section{CHROMOSOMAL INSTABILITY PROMOTES MUTATIONS THAT DECREASE VIRULENCE AND INCREASE SURVIVAL}

It has become dogma that once $P$. aeruginosa has colonized the lungs of CF patients, it adapts to a biofilm lifestyle to protect the bacterial community from hostile host defense and promote survival. The emergence of mucoid colony morphology is a hallmark of such adaptation and provides selective pressures that favor the occurrence of mutator phenotypes. These mutators in the bacterial community accumulate genetic changes resulting in altered phenotypes and gene expression profiles. The cause of the mutator phenotype is the inactivation/suppression of the methyl-directed mismatch repair (MMR) mechanism used to repair DNA replication errors and decrease the likelihood of homologous recombination events
(Kunkel and Erie, 2005). Mutations in this region are known to cause loss of DNA proof reading thereby increasing the likelihood of mutant phenotypes which may convey survival advantages (Leclerc et al., 1996). This "hypermutable" phenotype was observed in $20 \%$ of $P$. aeruginosa isolates collected from CF airways and absent in isolates collected from blood and from the airway of non-CF patients (Oliver et al., 2000). One of the major genes responsible for the MMR mechanism is mutS; inactivation of this gene effectively shuts off the MMR cascade. Genetic analysis of the mutS gene from the previously characterized hypermutable $P$. aeruginosa strain JMSMA7 revealed a 3.3-kb IS and an 8-nucleotide repeat which flanked a 54-nucleotide deletion (Oliver et al., 2000). Interestingly, contained within the 3.3$\mathrm{kb}$ IS lies another 1.2-kb IS element that is $90 \%$ homologous to IS 222 from the P. aeruginosa D3 phage (Kropinski et al., 1994; Oliver et al., 2000). This region was interpreted as a veritable "hot-spot" of recombination within the mutS gene promoting its loss of function and increasing the number of mutations (Oliver et al., 2002). An in-depth longitudinal study was undertaken by Smith et al. (2006) to examine the presence of the mutator phenotype in CF patients. The information gained from this study was used to further characterize the hypermutable isolates and determine the locations of these genetic errors. Sequencing of genes in two CF isolates taken at 6 months and a comparable isolate taken at 96 months during time course experiments revealed the accumulation of 68 mutations, wherein 13 were associated with virulence factors including genes associated with O-Ag biosynthesis (Smith et al., 2006). A continuing in-depth study using the genomes of these two isolates revealed an apparent increase in mutations within genes responsible for antibiotic resistance, as well as in lasR, a gene responsible for the regulation of quorum sensing in $P$. aeruginosa (Mena et al., 2008). The inactivation of lasR and subsequently rhlI in the hypermutable phenotype may result in a decrease of migA expression as indicated earlier by Yang et al. (2000). MigA is a glycosyltransferase responsible for the uncapped core OS phenotype, under the control of the RhlI-RhlR system (described below); when inactivated, the levels of MigA decrease causing an accumulation of "core-plus-one," a LPS glycoform with a single OSA repeat (Yang et al., 2000; Figure 1), a less virulent form of LPS. This degree of genotype plasticity is proposed to aid in the survival of bacteria within stressful environments during the transition to a chronic infection (Smith et al., 2006).

\section{QUORUM-SENSING ALTERS CORE OS STRUCTURE THAT AFFECTS O-AG LIGATION}

Cell density-dependent gene regulation plays an integral role in cellsurface virulence factor expression, altering gene expression based on population size (Whiteley et al., 1999). As previously mentioned, most $P$. aeruginosa CF isolates from chronically infected patients are devoid of OSA and begin to favor the typical "rough" phenotype, i.e., producing LPS that lacks the full-length $\mathrm{O}$ antigen side chain, being non-motile and non-piliated (Hancock et al., 1983). Although previous studies have shown the genetic relationship of the alginate-based mucoid phenotype (Ma et al., 1998), the regulation of changes governing the transition from smooth to rough LPS is not well defined. The "mucus inducible gene" migA (described above) is a putative glycosyltransferase and was discovered when $P$. aeruginosa was grown in the presence of CF mucus (Wang et al., 1996). Expression of the $m i g A$ gene was found to be a result of 
quorum sensing (Whiteley et al., 1999), dependent on the release of autoinducer molecules by $P$. aeruginosa into the local environment. When the bacterial density increases to an appropriate level, the local concentration of autoinducer molecules reaches a critical threshold past which they can consistently bind to transcription regulators across the entire cell population, resulting in alternative gene expression across the entire community (Fuqua et al., 1994). The migA gene was found to be under the control of RhlI-RhlR regulatory system, one of the two principal quorum-sensing systems, due to its severe decrease in expression in a rhlI-rhlR double knockout as compared to wildtype. Furthermore, it possesses an upstream lasbox-like sequence (CT-N $\mathrm{N}_{11}$ )-AG), known to be a quorum-sensing recognition site for quorum-sensing regulators (Yang et al., 2000). Interestingly, overexpression of migA resulted in a loss of "core-plusone" but not the higher molecular weight LPS, leading the authors to speculate the existence of a secondary glycosyltransferase (Yang et al., 2000). Recently that second glycosyltransferase was identified by our group as wapR, located 158-bp downstream of the core biosynthesis locus (Poon et al., 2008). Genetic and biophysical analysis of these two genes and their products revealed that both are responsible for core modifications in LPS biosynthesis (Figure 3). The expression of these genes results in an altered core structure: $m i g A$ is responsible for the addition of the $\mathrm{L}$-rhamnose ${ }^{\mathrm{A}}\left(\mathrm{L}-\mathrm{Rha}^{\mathrm{A}}\right)$ in the $\alpha 1 \rightarrow 6$ linkage, preventing the addition of $\mathrm{O}-\mathrm{Ag}$ to lipid A-core by the $\mathrm{O}-\mathrm{Ag}$ ligase WaaL (Yang et al., 2000; Poon et al., 2008). The wapR gene is responsible for the addition of the core sugar $\mathrm{L}-\mathrm{Rha}{ }^{\mathrm{B}}$, creating the favored linkage site for the addition of the O-Ag by WaaL (Poon et al., 2008). A genomic knockout of wapR resulted in the loss of higher molecular weight LPS bands, corresponding with the addition of O-Ag to lipid A-core. Work is currently underway in our laboratory to establish the relationship between migA and wapR gene expression. The cell density-dependent effects on gene regulation are of particular importance as CF isolates are often found in mature biofilms, a direct byproduct of quorum sensing.

\section{THE AGE OF TECHNOLOGY BROADENS GENE EXPRESSION INVESTIGATIONS}

In silico-based algorithms and bioinformatic methods have moved to the forefront of genomic research, performing a variety of predictions to provide a global view of genome expression profiles. When combined with microarray data, in silico modeling can be applied to examine an entire genome, particularly for investigating up and down regulations of genes throughout a longitudinal experiment. Using this approach, Oberhardt et al. (2010) examined the gene expression in a number of $\mathrm{CF}$ isolates throughout a progressive $\mathrm{CF}$ infection by a clonal strain of $P$. aeruginosa. They observed that the genes relating to LPS and capsule biosynthesis were downregulated during chronic CF infection. The development of new computerbased programs and ever-improving novel DNA sequencing techniques will help to broaden our understanding of the polymorphic nature of OSA of $P$. aeruginosa during CF infection.

\section{STRUCTURE, GENETICS, AND FUNCTION OF CPA (A BAND) DISCOVERY OF CPA}

In the 1980s, CPA was detected to be a $P$. aeruginosa antigen that reacted with a human monoclonal antibody produced by Sawada's group (Sawada et al., 1985). Further analysis found the antigen to be a neutral polysaccharide composed of D-rhamnose (D-Rha) that is separable as well as structurally and immunologically distinct from the predominant OSA (Yokota et al., 1987; Kocharova et al., 1988; Rivera et al., 1988). In a study by McGroarty's group, the authors used gel filtration chromatography and a buffer containing deoxycholate, which helped to disperse LPS from micelles and aggregates, to obtain two separate fractions of surface polysaccharide from $P$. aeruginosa (Rivera et al., 1988). The fast-migrating fraction contained OSA (named B band) that was reactive to serotype-specific antibodies, while the slower-migrating fraction (CPA, i.e., A band) did not react with any of the mAbs that the Lam laboratory had raised against the IATS serotypes. Upon receiving the CPA from McGroarty, our group raised a number of hybridoma cell lines (e.g., N1C9, N1F10) that secreted mAbs that are specific against

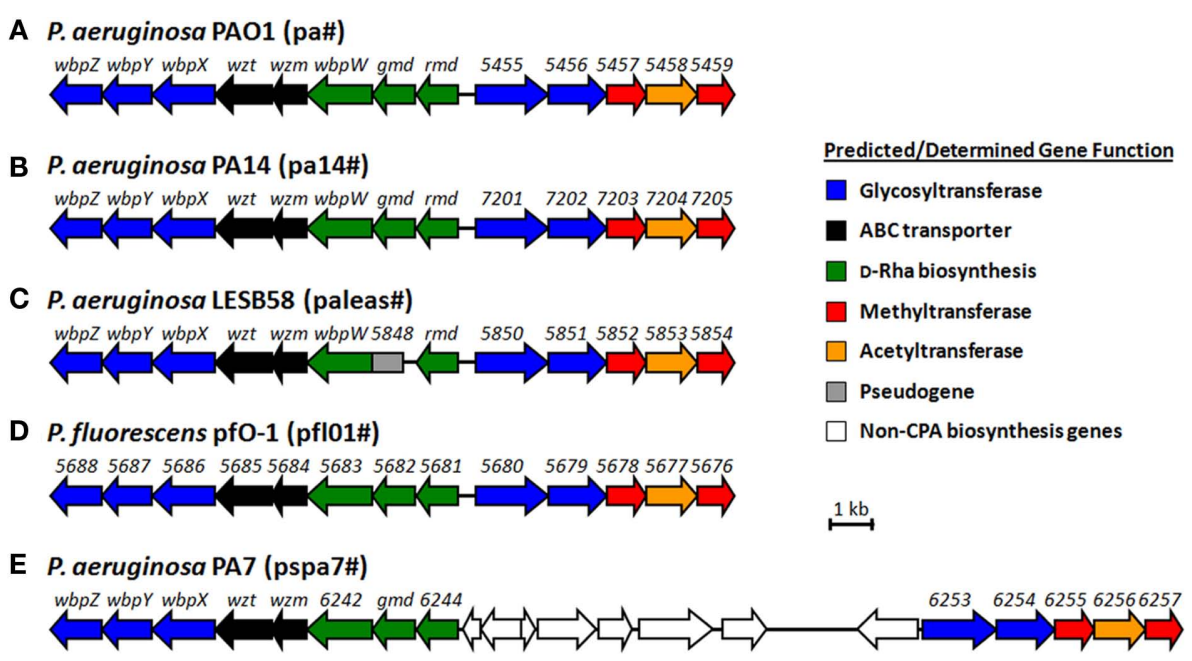

FIGURE 3 | Proposed CPA gene clusters of (A) P aeruginosa PA01, (B) PA14, (C) LESB58, (E) PA7, and (D) P. fluorescens pfO-1. The organism-Specific identifier for numbered genes of unknown function is indicated in brackets beside each organism. 
CPA. Using mAb N1F10 in dot-blot and Western-immunoblotting analyses, the presence of CPA was detected in 14 of the 20 P. aeruginosa IATS serotypes. The strains that did not react to the mAb belong to serotypes O7, O12, O13, O14, O15, and O16 (Lam et al., 1989; Currie et al., 1995). However, a majority of clinical P. aeruginosa isolates examined since then were found to be devoid of OSA but produce CPA as the predominant surface polysaccharide antigen (Lam et al., 1989; Weisner et al., 2007). In a separate study, CPA was found to be a receptor for bacteriophage A7, indicating its significance as a cell-surface polysaccharide component of $P$. aeruginosa and its role in the co-evolution with temperate bacteriophages (Rivera et al., 1992).

\section{STRUCTURAL STUDY OF CPA}

Structural elucidation of CPA from different $P$. aeruginosa strains has been reported. Yokota's group was the first to discover that the predominant structure of the common polysaccharide from P. aeruginosa strain IID 1008 (ATCC 27584; Yokota et al., 1987) reactive to a human $\mathrm{mAb}$ is composed of a trisaccharide repeating unit: $\rightarrow 3$ ) $\mathrm{D}-\mathrm{Rha}(\alpha 1 \rightarrow 3) \mathrm{D}-\mathrm{Rha}(\alpha 1 \rightarrow 2) \mathrm{D}-\mathrm{Rha}(\alpha 1 \rightarrow$. Our group prepared CPA from PAO1 (serotype O5; Arsenault et al., 1991) and by using high-field nuclear magnetic resonance (NMR) and mass spectrometry (MS) methods, we collected data to show that this neutral polysaccharide contains a D-rhamnan with the same structural repeat as demonstrated by Yokota et al. (1987). Two other groups who examined CPA from a serotype O7 strain (Lanyi-Bergan classification; Kocharova et al., 1988) and strain PA103 (serotype O11; Choudhury et al., 2005) also observed the same trisaccharide repeat structure. However, aside from the predominant D-Rha trisaccharide repeat units, small amounts of other components have also been reported with less consistency among the different studies. For example, the presence of 3-O-methylrhamnose, ribose, mannose, glucose, and a 3-O-methylhexose have been detected from CPA prepared from strain PAO1 (Arsenault et al., 1991); 3-O-methyl6-deoxyhexose, glucose, xylose, alanine, galactosamine, and phosphorus have all been reported as components of CPA fractions for strain IID 1008 (ATCC 27584; Yokota et al., 1987). Glucose, mannose, and phosphate have been found in the study of CPA from the O7 strain (Kocharova et al., 1988), while mannose and GlcNAc, as well as small amounts of $O$ - and $N$-acetyl substitutions, were found in the CPA from strain PA103 (Choudhury et al., 2005). These differences reported in the minor components of CPA could be due to several factors including genuine strain differences, the details in the preparation of CPA, and the sensitivity and accuracy of the detection methods used. In conclusion, the precise structure of CPA has not been defined to date. Further study is currently underway in our lab to determine the identity of the initiating sugar, the terminal sugar, the position and amount of other sugar components, as well as the degree and position of the methylation and acetylation modifications of CPA from strain PAO1.

\section{GENETICS OF CPA BIOSYNTHESIS}

A cosmid clone pFV3 that is able to restore CPA biosynthesis in a CPA-deficient mutant (strain AK1401) was first obtained from a cosmid library of $P$. aeruginosa prepared from strain PAO1. Mutant strain AK1401 was a phage-resistant mutant derived from the PAO1 background (Lightfoot and Lam, 1991). When expressed in trans, cosmid pFV3 was also found to be able to restore CPA biosynthesis in five (O7, O13, O14, O15, and O16) out of the six IATS serotypes that lacked CPA LPS (Lightfoot and Lam, 1991). Sequencing and genetic analysis of this clone revealed a cluster of eight genes (Figure 3,rmd-wbpZ) that are required for CPA biosynthesis. Our group went on to construct a non-polar knockout mutant of each of these genes (Rocchetta and Lam, 1997; Rocchetta et al., 1998a,b). Three of the genes rmd, gmd, wbpW (pa5454, pa5453, pa5452) plus another gene located in the alginate biosynthesis cluster, algC (pa5322), encode enzymes responsible for the biosynthesis of GDP-D-Rha, the nucleotide sugar precursor for CPA. The glycosyltransferase gene $w b p L$ located in the OSA gene cluster described earlier was found to be required for the initiation of both CPA and OSA assembly (Rocchetta et al., 1998a). Another three genes in the cluster, $w b p X, w b p Y$, and $w b p Z$ ( $p a 5449$, pa5448, and pa5447), encode putative rhamnosyltransferases responsible for the specific linkages of the $\alpha 1 \rightarrow 3, \alpha 1 \rightarrow 3, \alpha 1 \rightarrow 2$ bonds that form the D-Rha trisaccharide repeating unit (Rocchetta et al., 1998a). The last two genes, wzm and wzt (pa5451 and pa5450), encode proteins for an $\mathrm{ABC}$ transport system that transfers the UndPP-linked CPA polymer precursor across the IM to the periplasmic surface where CPA is ligated to lipid A-core to complete its synthesis (Rocchetta and Lam, 1997). Southern-blotting analysis revealed that this cluster of eight genes is present in all of the 20 IATS reference strains, although some strains that do not produce CPA (O12, O13, O15, and $\mathrm{O} 16$ ) showed variation in the blotting profiles suggesting DNA rearrangement within the cluster (Currie et al., 1995).

In recent years, the genomes of several $P$. aeruginosa strains have been sequenced including PAO1 (serotype O5) (Stover et al., 2000), PA14 (serotype O10) (Lee et al., 2006), PA7 (a multidrug resistance serotype O12 strain; Roy et al., 2010), and the NT Liverpool Epidemic strain LESB58 (Winstanley et al., 2009). LESB58 has a rough LPS phenotype devoid of OSA; however, its genome sequence consists of the OSA biosynthesis locus that shares a high degree of homology and gene organization with the serotype O6 OSA LPS cluster sequenced by Raymond et al. (2002). Analysis of these genomes revealed that all four strains contain the $r m d$-wbpZ eight-gene cluster in a conserved manner. However, the clinical isolate LESB58 contains a non-functional gmd that can be deemed a pseudogene. In three of the sequenced genomes (PAO1, PA14, and LESB58), immediately adjacent to the $r m d-w b p Z$ eight-gene cluster and located in the opposite strand, a five-gene cluster (pa5455-pa5459 in PAO1, pa14_7201-pa14_7205 in PA14, and paleas_5850-paleas_5854 in LESB58) was also present in a conserved manner (Figures $3 \mathrm{~A}-\mathrm{C}$ ). This cluster of genes encoding putative glycosyltransferases (the first two genes in the cluster, blue), methyltransferases (the third and the fifth genes in the cluster, red) and an acetyltransferase (the fourth gene in the cluster, orange), was also proposed to be involved in CPA biosynthesis and modification (King et al., 2009). Mutation and complementation analyses of these five genes clearly showed that all five are required for CPA biosynthesis (Hao and Lam, unpublished data). This five-gene cluster is also found in the genome of strain PA7 (serotype O12; Figure 3E, pspa7_6253-pspa7_6257). However, unlike in the aforementioned three strains, this five-gene cluster is located on the same strand and is separated from the $r m d-w b p Z$ eight-gene cluster by a 10-kb DNA fragment in PA7 (Figure 3). This could have resulted from a chromosomal rearrangement event 
and might have disrupted the promoter region of this gene cluster, which would explain the lack of CPA expression in this strain. We also found that this genomic region from strain PA7 showed a much lower sequence identity to that of the other three strains. The strains PAO1, PA14, and LESB58 share more than 95\% sequence identity in most of the proteins encoded by genes of the CPA biosynthesis cluster, while PA7 showed less than 50\% identity to these three strains. This may explain why the cosmid pFV3 did not complement CPA biosynthesis in this serotype while still being able to do so for the other five serotypes that lack CPA LPS. Interestingly, we found that homologous CPA biosynthesis genes are also present in the genome of P. fluorescens pfO-1 (Silby et al., 2009), in a conserved manner similar to P. aeruginosa PAO1 and PA14 (Figure 3D), showing $54-75 \%$ amino acid sequence identity to these two strains. To date there is no report about the structure of LPS of $P$. fluorescens pfO-1. It would be interesting to study whether this strain produces the same CPA LPS, and whether it also produces two types of LPS as in $P$. aeruginosa.

The same structure of D-Rha repeating units $[\rightarrow 3)$ D-Rha $(\alpha 1 \rightarrow 3)$ D-Rha $(\alpha 1 \rightarrow 2)$ D-Rha $(\alpha 1 \rightarrow)$ ] has been reported for the LPS of several other bacterial species including the plant pathogen Xanthomonas campestris pv. phaseolivar. fuscans (Senchenkova et al., 2002), the opportunistic human pathogen Stenotrophomonas maltophilia serotype O7 (Winn and Wilkinson, 1998), P. syringae strains (Ovod et al., 1996), and a Burkholderia cepecia strain (Cerantola and Montrozier, 1997). However, to our knowledge, the OSA biosynthesis genes have not been identified and investigated in any of these bacterial strains.

\section{FUNCTIONAL STUDY OF CPA}

Most $P$. aeruginosa strains simultaneously produce both OSAcontaining LPS and CPA-containing LPS, with the former being the more proportionally predominant LPS species. However, it was reported that due to long-term selective pressure against the OSA (which is the more immunogenic of the two O-Ag glycoforms), $\mathrm{CPA}$ is apparently selectively maintained as the preferred $\mathrm{O}-\mathrm{Ag}$ on the cell surface of $P$. aeruginosa during chronic lung infection in CF patients, and becomes the major LPS antigen over time (Hancock et al., 1983; Lam et al., 1989).

Thus far, there is only limited information about the biological function of CPA besides being part of the P. aeruginosa cell wall. Our lab has demonstrated in a cell adhesion assay study that a rmd mutant of $P$. aeruginosa, defective in D-Rha biosynthesis and thereby CPA production, is significantly less efficient in adhering to cultured human bronchial epithelial cells, suggesting that CPA may play an important role in adherence of $P$. aeruginosa to tissues (Matewish, 2004). More work is currently underway to investigate the significance of CPA for $P$. aeruginosa to attach to different surfaces using biophysical techniques based on atomic force microscopy (AFM).

\section{CONTRIBUTION OF VARIATIONS IN CORE OLIGOSACCHARIDE TO LPS DIVERSITY}

For the sake of full coverage of each region of the LPS molecule that contributes to diversity in the LPS produced by $P$. aeruginosa, in this section, we will briefly discuss the variability in core OS structures. Our group has recently published a review on the structural diversity of the complete and the truncated core OS (Kocíncová and Lam, 2011), hence more details on structural diversity of core OS can be found there. In general, core OS, which is the linker region between $\mathrm{O}-\mathrm{Ag}$ and lipid A can be divided into two regions, namely, the inner and outer core.

\section{STRUCTURE OF INNER CORE OS}

Composition of the sugar constituents in inner core OS is identical among $P$. aeruginosa strains and it consists of two residues of 3-deoxy-D-manno-octulosonic acid $\left(\mathrm{Kdo}^{\mathrm{I}}\right.$ and $\left.\mathrm{Kdo}^{\mathrm{II}}\right)$ and two residues of L-glycero-D-manno-heptose ( $\mathrm{Hep}^{\mathrm{I}}$ and $\mathrm{Hep}^{\mathrm{II}}$; Figure 4). The inner core is highly conserved when compared to other Gramnegative bacteria. A distinguishing feature of the $P$. aeruginosa inner core is a high degree of phosphorylation that is essential for viability of $P$. aeruginosa, since mutation of either of the two genes (wapP and waaP) encoding kinases that are responsible for adding phosphate groups to the inner core heptoses is lethal (Walsh et al., 2000). In most $P$. aeruginosa strains, three phosphorylation sites have been identified; positions 2 and 4 on $\mathrm{Hep}^{\mathrm{I}}$ and position 6 on $\mathrm{Hep}^{\text {II }}$. In a CF isolate, $\mathrm{Hep}^{\mathrm{II}}$ has been shown to possess an additional phosphorylation site on position 4 (Knirel et al., 2006). In theory, monophosphate, diphosphate, or triphosphate groups might occupy each of the phosphorylation sites (Kooistra et al., 2003; Choudhury et al., 2005; Bystrova et al., 2006). Some of the analyzed $P$. aeruginosa strains have shown the non-stoichiometric substitution of a phosphate group on position 2 of $\mathrm{Hep}^{\mathrm{I}}$ by ethanolamine-phosphate or ethanolamine-diphosphate (Bystrova et al., 2006). However, Knirel et al. (2006) suggested that the actual content of phosphates and ethanolamine-phosphates in the inner core might be higher, since these phosphate groups can be released from the core during preparation of LPS prior to structural analyses. In addition to phosphorylation, Hep ${ }^{\text {II }}$ is modified with another non-carbohydrate substituent, namely an $\mathrm{O}$-carbamoyl group on position 7 (Beckmann et al., 1995).

\section{STRUCTURE OF OUTER CORE OS}

The outer core of $P$. aeruginosa LPS is composed of one D-galactosamine (GalN), one L-Rha, and three or four D-glucose $\left(\mathrm{Glc}^{\mathrm{I}}-\mathrm{Glc}^{\mathrm{IV}}\right)$ residues. GalN is further substituted on position 2 with an alanyl (Ala) group or in some truncated core structures with an acetyl group (Sanchez Carballo et al., 1999; Choudhury et al., 2008). The outer core OS of P. aeruginosa has a unique feature; it exists in two structurally distinct glycoforms, called "uncapped" and "capped" (King et al., 2009). These two glycoforms basically differ in position and linkage of an L-Rha residue in each structure. The capped glycoform is covalently attached to $\mathrm{O}-\mathrm{Ag}$ on $\mathrm{L}-\mathrm{Rha}^{\mathrm{B}}$ that is 1,3 -linked to Glc ${ }^{\mathrm{I}}$, whereas the uncapped glycoform cannot be substituted with O-Ag and it contains an $\mathrm{L}^{-\mathrm{Rh}^{\mathrm{A}}}$ that is 1,6-linked to Glc ${ }^{\mathrm{II}}$ (Figure 4). The presence of this L-Rha ${ }^{A}$ likely causes steric hindrance and prevents attachment of O-Ag to the uncapped core OS; it is also possible that this 1,6-linked L-Rha cannot be recognized by WaaL (O-Ag ligase) as part of the core OS receptor during the $\mathrm{O}$-Ag ligation process.

Another variability in sugar composition of core OS is the presence or absence of a fourth Glc residue ( $\mathrm{Glc}^{\mathrm{IV}}$ ) in the uncapped core OS; among the core OSs of the 20 IATS serotypes, $\mathrm{Glc}^{\mathrm{IV}}$ is present in only nine $(\mathrm{O} 2, \mathrm{O} 5, \mathrm{O} 7, \mathrm{O} 8, \mathrm{O} 10, \mathrm{O} 16, \mathrm{O} 18, \mathrm{O} 19$, and O20; De Kievit and 


\section{A Uncapped core}

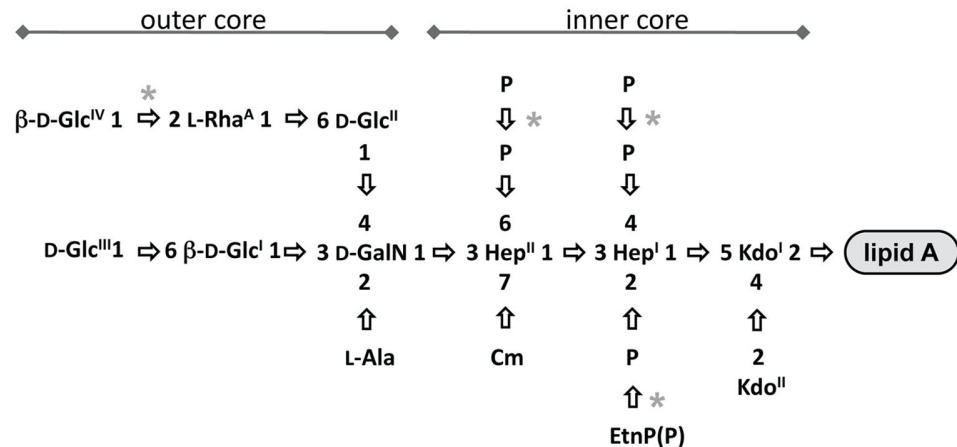

B Capped core

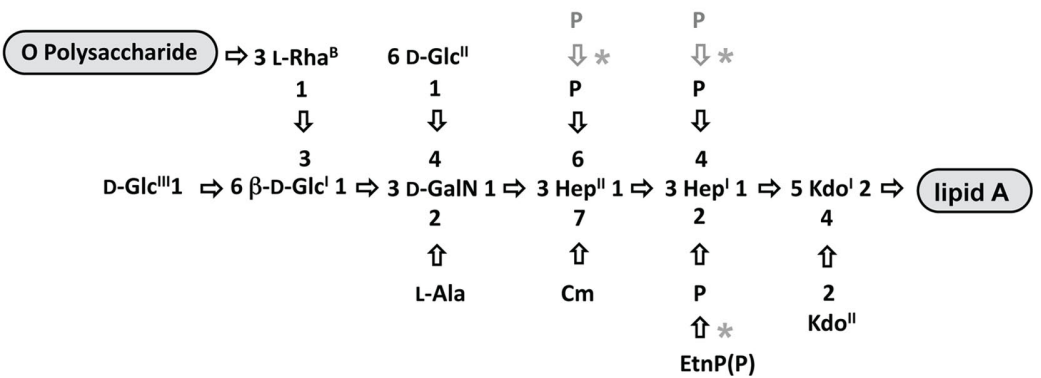

FIGURE 4 | Structures of uncapped and capped glycoforms. The structures of the uncapped core oligosaccharide (A), and capped core oligosaccharide (B) are depicted. All the sugars shown have $\alpha$ configuration unless otherwise indicated. Asterisks depict variable substitutions, acetylation sites are shown since they have not been precisely identified. Ala, alanine; Cm, carbamoyl; Etn, ethanolamine; GalN, 2-amino-2-deoxy-galactose (galactosamine); Glc, glucose; Hep, L-glycero-D-mannoheptose; Kdo, 3-deoxy-D-manno-oct-2-ulosonic acid; Rha, rhamnose. Adapted from King et al. (2009).

Lam, 1994; Bystrova et al., 2006). Additionally, a variable non-sugar substitution found in outer core $\mathrm{OS}$ is $\mathrm{O}$-acetylation. $P$. aeruginosa strains display diversity in the degree of $\mathrm{O}$-acetylation ranging from none to five acetyl groups (Bystrova et al., 2006). Since O-acetylation is non-stoichiometric, attempts to precisely identify and quantify all acetylated residues have been difficult. Thus far, only two specific residues have been found to be $\mathrm{O}$-acetylated: $\mathrm{Rha}^{\mathrm{A}}$, particularly when this residue is not further linked to $\mathrm{Glc}^{\mathrm{IV}}$, and $\mathrm{Glc}^{\mathrm{II}}$, as observed in a number of $P$. aeruginosa mutants with defects in core OS biosynthesis producing truncated core OS (Bystrova et al., 2006; Poon et al., 2008).

\section{SPONTANEOUS CORE TRUNCATIONS}

As mentioned above, phosphorylation of inner core heptoses is essential for $P$. aeruginosa cells. Each constituent of the entire inner core seems to be required for viability of $P$. aeruginosa; thus far all of the truncated OS structures that have been examined exhibited a complete inner core, with defects only found in the outer core residues (Sadovskaya et al., 1998; Sanchez Carballo et al., 1999; Kooistra et al., 2003; Choudhury et al., 2005). Preliminary observations also suggested that GalN, the first residue of the outer core, might be essential for viability. This assumption was based on the inability to construct a mutant of wapG, which encodes a glycosyltransferase presumably responsible for transferring a GalN residue to the Hep residue in the core (Matewish, 2004). A spontaneous mutation causing truncation of core OS under a selective pressure could be a significant source of core diversity. Core OS has been reported to be a receptor for a number of bacteriophages and pyocins (Jarrell and Kropinski, 1981a,b; Temple et al., 1986; Yokota et al., 1994; Michel-Briand and Baysse, 2002). For more details, see the section in this review on the role of LPS in host-pathogen interactions. In earlier studies of $P$. aeruginosa LPS biosynthesis, bacteriophages E79 and 2 Lindberg were used to select for spontaneous rough mutants that also had truncation within the core OS (Jarrell and Kropinski, 1981a,b; Dasgupta et al., 1994). Two varieties of outer core truncations providing resistance to bacteriophages have been described, more specifically, the outer core of these structures in the mutant bacterial strains were composed of either (i) the first residue of outer core, GalN (representing the deepest truncation of core OS structure ever found in P. aeruginosa) or (ii) a disaccharide GalN-Glc (Masoud et al., 1994; Sadovskaya et al., 1998; Sanchez Carballo et al., 1999). Similarly, pyocins (i.e., "defective phages") produced by $P$. aeruginosa, that are able to kill susceptible cells of the same species but are unable to replicate within cells (Michel-Briand and Baysse, 2002), have been used to select for spontaneous rough mutants aiming to generate ones with truncations within the core region (Koval and Meadow, 1977). Another strategy to search for strains with core OS truncations has been to select for spontaneous mutants that would be resistant to a cationic antibiotic; our group used increasing concentrations of gentamicin to select for drug-resistant mutants (Dasgupta et al., 1994). However, the core OS structures from these gentamicin and pyocin-resistant strains have yet to be elucidated, and as such their chemical compositions remain unknown. 


\section{GENETICS OF CORE DIVERSITY DUE TO GLYCOSYLTRANSFERASES}

Pseudomonas aeruginosa genomes possess a gene cluster (pa4996pa5012) encoding proteins that are known to be involved in core OS biosynthesis: HldE, MsbA, PA4998, WaaL, WapR, PA5001, PA5002, PA5003, WapH, WapO, PA5006, WapQ, WapP, WaaP, WapG, WaaC, and WaaF. The respective function of each of these proteins (either demonstrated or proposed based on homology comparisons) has been summarized (Table 3; for more detailed description, see a recent review by our group (King et al., 2009). Apart from the presence or absence of the $\mathrm{Glc}^{\mathrm{IV}}$ residue as a terminal sugar in uncapped core OS, the structures of core OS among $P$. aeruginosa strains are relatively conserved with no strain-to-strain variability in sugar composition. This observation is consistent with the discovery that the genes in the locus for core biosynthesis are well conserved among $P$. aeruginosa strains whose genomes have been sequenced. The amino acid identity of the gene products in this locus from one strain to the next is relatively high ranging from 77 to $100 \%$. In addition to genes that encode kinases and heptosyltransferases, this

Table 3 | Genes involved or potentially involved in the core OS biosynthesis of $P$. aeruginosa.

\begin{tabular}{ll}
\hline Gene & $\begin{array}{l}\text { Proposed/demonstrated References } \\
\text { function }\end{array}$ \\
\hline
\end{tabular}

\begin{tabular}{|c|c|c|}
\hline \multicolumn{3}{|c|}{ CORE BIOSYNTHESIS GENE CLUSTER (PA4996-PA5012) } \\
\hline hldE/pa4996 & Heptose biosynthesis & King et al. (2009) \\
\hline$m s b A^{\# / p a 4997}$ & Transport lipid A-core & Ghanei et al. (2007) \\
\hline pa4998 & Kinase & King et al. (2009) \\
\hline waaL\#/pa4999 & $\mathrm{O}$ antigen ligase & $\begin{array}{l}\text { Abeyrathne et al. } \\
\text { (2005), Abeyrathne } \\
\text { and Lam (2007) }\end{array}$ \\
\hline $\boldsymbol{w a p R} / \mathrm{pa5000}$ & Glycosyltransferase $\left(\right.$ Rha $\left.^{\mathrm{B}}\right)$ & Poon et al. (2008) \\
\hline pa5001 & Glycosyltransferase & King et al. (2009) \\
\hline pa5002 & Unknown & \\
\hline pa5003 & Unknown & \\
\hline wapH/pa5004 & Glycosyltransferase (GIc") & Matewish (2004) \\
\hline wapO/pa5005 & Carbamoyltransferase & (King et al. (2009) \\
\hline pa5006 & Kinase & King et al. (2009) \\
\hline wapQ/pa5007 & Heptose kinase & Walsh et al. (2000) \\
\hline wapP/Pa5008 & Heptose kinase & $\begin{array}{l}\text { Walsh et al. (2000), } \\
\text { To (2006) }\end{array}$ \\
\hline waaP/pa5009 & $\begin{array}{l}\text { Heptose kinase: position } \\
4 \text { of Hepl }\end{array}$ & $\begin{array}{l}\text { Walsh et al. (2000), } \\
\text { Zhao and Lam (2002), } \\
\text { Zhao et al. (2002) }\end{array}$ \\
\hline wapG/pa5010 & Glycosyltransferase (GalN) & \\
\hline waaC/pa5011 & Glycosyltransferase (Hep') & De Kievit and Lam (1997) \\
\hline waaF/pa5012 & Glycosyltransferase (Hep") & De Kievit and Lam (1997) \\
\hline \multicolumn{3}{|c|}{ GENES LOCATED OUTSIDE OFTHE CORE BIOSYNTHESIS CLUSTER } \\
\hline wapB/pa1014 & glycosyltransferase (Glc $\left.{ }^{1 V}\right)$ & Kocíncová et al. (2011) \\
\hline migA/pa0705 & glycosyltransferase $\left(\mathrm{Rha}^{\mathrm{A}}\right)$ & Poon et al. (2008) \\
\hline waaA/pa4988 & $\begin{array}{l}\text { glycosyltransferase: } \\
\text { (Kdo', Kdo") }\end{array}$ & King et al. (2009) \\
\hline
\end{tabular}

* Indicates genes involved in cellular processes other than core biosynthesis. Bold font indicates that biochemical or genetic evidence of involvement in P. aeruginosa core biosynthesis exists. cluster contains genes that are involved in the transportation of lipid $\mathrm{A}$ and ligation of $\mathrm{O}-\mathrm{Ag}$ to the core ( $m s b A$ and waaL, respectively). Two other genes, pa5002 and pa5003 have not been characterized; therefore, their functions are at present unknown.

Our group has reported the characterization of two transferase genes, migA (described above) and waaA, that are important for core OS biosynthesis, but are localized outside the usual core LPS gene locus. The waaA gene encodes a putative Kdo transferase (King et al., 2009). More recently, we have characterized a homolog of $m i g A$ that is designated as wapR. The wapR gene turned out to be localized within the core OS gene cluster. Characterization of WapR showed that it is responsible for the transfer of $\mathrm{L}-\mathrm{Rha}^{\mathrm{B}}$, the other outer core rhamnose residue that is 1,6-linked to the $\mathrm{Glc}^{\mathrm{I}}$ of the capped core OS (Poon et al., 2008). We hypothesize that the ratio between expression levels of migA and wapR would influence the amount of capped and uncapped core OS being produced. Studies to understand the regulation of $w a p R$ are currently underway in our laboratory. Both putative rhamnosyltransferase enzymes, MigA and WapR, presumably utilize the same substrates, TDP-L-Rha as a sugar donor and core OS lacking L-Rha residues as an acceptor molecule. Therefore, they compete for the enzyme substrates and should impact on amounts of capped and uncapped glycoforms being produced. For instance, overproduction of MigA favors synthesis of uncapped core, whereas an elevated level of WapR activity leads to higher amounts of capped core substituted with O-Ag. It is plausible that under certain conditions migA is upregulated while wapR is downregulated (or vice versa), which may consequently influence the amount of $\mathrm{O}-\mathrm{Ag}$ on the cell surface of $P$. aeruginosa.

We recently discovered yet another transferase gene called $w a p B$, which shares sequence homologies with both migA and $w a p R$. The $w a p B$ gene encodes a putative 1,2-glucosyltransferase that is required for transfer of terminal Glc ${ }^{\mathrm{IV}}$ to uncapped core OS (Kocíncová et al., 2011). As not all of the P. aeruginosa strains possess $\mathrm{Glc}^{\mathrm{IV}}$ as a terminal sugar residue in their uncapped core OS, not all of the $P$. aeruginosa strains have the wapB gene. For instance, this gene is absent from the sequenced genome of P. aeruginosa PA7.

Other variability in the structure of the P. aeruginosa core OS arises from the different degrees of phosphorylation (including ethanolamine-phosphate) and acetylation patterns. However, the variability of these phosphatidyl or acetyl substitutions is nonstoichiometric and the genetic elements that account for these minor substitutions are unknown at present. Additionally, it has yet to be determined what role (if any) genetic events such as mutations or mobile element insertions in core OS genes have played in the truncation of core OS, when rough LPS mutants were selected for resistance to bacteriophages/pyocins or antibiotics. Therefore, there are obvious areas concerning core biosynthesis and regulation that require further investigation.

\section{STRUCTURE AND FUNCTION DIVERSITY OF LIPID A STRUCTURAL DIVERSITY OF P. AERUGINOSA LIPID A}

The lipid A domain of LPS is a glucosamine-based lipid that anchors the LPS in the bacterial outer membrane (OM). The structure of $P$. aeruginosa lipid A has been studied in great detail using both MS and NMR techniques, and it has been reviewed by several groups (Knirel et al., 2006; King et al., 2009; Moskowitz and Ernst, 2010). Similar to lipid A of other Gram-negative bacteria, P. aeruginosa 
lipid $\mathrm{A}$ is composed of a diglucosamine biphosphate backbone $\left[4-\mathrm{P}-\beta\right.$-D-GlcN ${ }^{\mathrm{II}-}(1 \rightarrow 6)-\alpha-\mathrm{D}-\mathrm{GlcN}^{\mathrm{I}}(1 \rightarrow \mathrm{P}]$, and $O$ - and $N$ - linked primary and secondary fatty acids. The major structural differences of lipid A are observed in the number, the position, the nature of the linked acyl groups, and the modification of the phosphate groups (Figure 5). For example, the chain lengths of the fatty acids attached to lipid $A$ of $P$. aeruginosa $\left(\mathrm{C}_{10} / \mathrm{C}_{12}\right)$ are shorter than those of E. coli and Salmonella enterica sv. Typhimurium $\left(\mathrm{C}_{12} / \mathrm{C}_{14}\right.$; Trent, 2004). Heterogeneity of lipid A structure has also been observed within different $P$. aeruginosa strains, which arises from different growth conditions and isolation sources.

The lipid A of laboratory-adapted $P$. aeruginosa strains (including $\mathrm{PAO} 1, \mathrm{PAK}$, and PA14) grown in rich medium was found to exhibit a hexa-acylated form ( $25 \%$; Figure 5 lipid A form A) or a pentaacylated form ( $75 \%$; Figure 5 lipid A form B; Bhat et al., 1990; Kulshin et al., 1991; Ernst et al., 1999; Moskowitz et al., 2004). The hexa-acylated form is a symmetrically acylated structure, with each sugar containing an $\mathrm{N}$-linked 12:0(3-OH) [I-3-hydroxylauroyl] group at the 2 position, an $\mathrm{O}$-linked 10:0(3-OH) [I-3-hydroxydecanoyl] group at the 3 position, and a secondary 12:0 (lauroyl) group linked to the $3-\mathrm{OH}$ group of the primary $N$-linked $12: 0(3-\mathrm{OH})$ at position 2 (lipid A form A). Either or both of the secondary acyl groups could be non-stoichiometrically 2-hydroxylated (Figure 5 red labeled), converting 12:0 to 12:0(2-OH) (Kulshin et al., 1991). The penta-acylated lipid A form, which is the predominant ( $75 \%)$ lipid A form of laboratory $P$. aeruginosa strains, lacks the primary $O$-linked acyl substitution at position 3 of the $\mathrm{GlcN}^{\mathrm{I}}$ (Figure 5, lipid A form B; Kulshin et al., 1991).

As has been demonstrated in enteric bacteria such as $S$. enterica (Guo et al., 1997, 1998), P. aeruginosa lipid A adopts different modifications in response to different environmental conditions encountered such as different growth medium and during human infection. For example, clinically isolated $P$. aeruginosa strains produce lipid A with modified structures. Lipid A from P. aeruginosa isolated from patients with acute clinical infections (such as blood, ear, eye, and urinary tract) or chronic non-CF infections such as bronchiectasis has a penta-acylated form that lacks the secondary acyl group at position 2 of the sugar $\mathrm{GlcN}^{\mathrm{I}}$ (Figure 5 lipid A form C; Ernst et al., 1999, 2003). Three different types of modifications have been observed for the lipid A structure of $P$. aeruginosa isolates from CF patient airways. The first type of modification is observed in the majority of CF $P$. aeruginosa isolates: the addition of an $\mathrm{O}$-linked secondary palmitate $(16: 0)$ to the $3-\mathrm{OH}$ group of 10:0 $(3-\mathrm{OH})$ at the $3^{\prime}$ position in sugar GlcN ${ }^{\mathrm{II}}$ (Figure 5 lipid A form D, blue; Guo et al., 1997, 1998). Less than half of CF isolates examined by the Miller group showed a second type of modification to lipid A, the non-stoichiometric addition of aminoarabinose (4-amino-4-deoxy-L-arabinose, Ara4N) to either or both of the

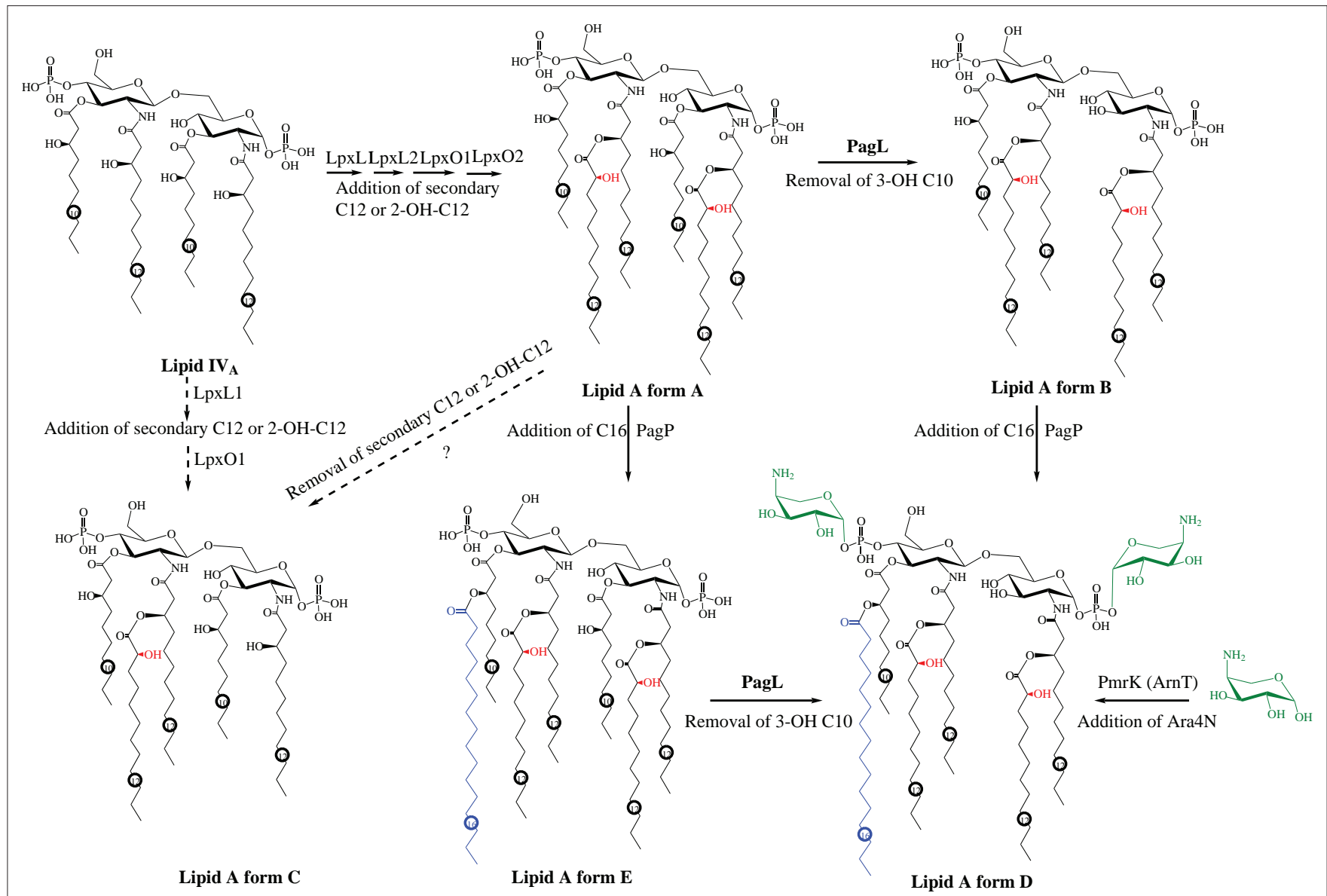

FIGURE 5 | Different lipid A forms of $P$. aeruginosa and the proposed biosynthesis and modification pathway. 
terminal phosphates (Figure 5 lipid A form D, green; Ernst et al., 2007). A hepta-acylated lipid A (Figure 1 lipid A form E) found only in P. aeruginosa isolates from CF patients with very severe lung disease resulted from a third type of modification: the retention of the primary $O$-linked 10:0(3-OH) group at the 3 position of $\mathrm{GlcN}^{\mathrm{I}}$ (Ernst et al., 2003, 2007). Interestingly, the lipid A modifications observed in CF airway isolates (i.e., addition of palmitate and aminoarabinose) could be induced in laboratory strains, strains isolated from the environment, or non-CF clinical isolates under certain growth conditions including low $\mathrm{Mg}^{2+}$ concentration or the presence of cationic antimicrobial peptides (CAMPs) such as polymyxin $\mathrm{B}$, indicating the enzymatic pathways for these modifications were intact and inducible in these strains (Bhat et al., 1990; Ernst et al., 1999, 2003; Bedoux et al., 2004).

\section{PROPOSED BIOSYNTHESIS AND MODIFICATION PATHWAY OF LIPID A}

Over the past 20 years, the biosynthesis pathway of lipid A has first been experimentally determined in E. coli as well as other enteric bacteria and reviewed by Raetz and Whitfield (2002) and Trent (2004). Bioinformatics analysis indicates that the general scheme of lipid A biosynthesis pathways are highly conserved among Gram-negative bacteria, although various modifications are present in different bacteria (Trent, 2004). In P. aeruginosa, in contrast to the extensive and detailed structural elucidation of lipid A, most aspects of the biosynthesis pathway have not been investigated experimentally, perhaps due to the fact that the genetics of lipid A biosynthesis were so thoroughly studied in enteric bacteria and that the pathway is relatively conserved. The current assumption about the biosynthesis pathways is mainly based on the identification of homologs to E. coli genes. Since all of the corresponding homologous genes encoding enzymes required for the biosynthesis of the important lipid A structure precursor lipid $\mathrm{IV}_{\mathrm{A}}$ (Figure 5; including the primary acyltransferases LpxA and $\mathrm{LpxD}$, the nucleotidase $\mathrm{LpxH}$, the disaccharide synthase LpxB, and the kinase LpxK) were identified in the genome of $P$. aeruginosa, the biosynthesis of the lipid $\mathrm{IV}_{\mathrm{A}}$ analog of $P$. aeruginosa is thought to be executed in a conserved manner as in E. coli and S. enterica. A detailed description of the proposed biosynthesis pathway of lipid $\mathrm{IV}_{\mathrm{A}}$ was recently reviewed by our group (King et al., 2009). Not surprisingly, the lipid A primary acyl chain length of different bacteria is determined by the chain length preference of the acyltransferase LpxA and LpxD (Dotson et al., 1998; Wyckoff et al., 1998).

Different forms of lipid A could then be synthesized and modified from lipid $\mathrm{IV}_{\mathrm{A}}$ by different enzymes depending on the environmental conditions (a proposed pathway is depicted in Figure 5). Two secondary acyltransferases (LpxL1 and LpxL2, encoded by pa3243 and pa0011, respectively) are proposed to transfer the secondary lauroyl groups to lipid $\mathrm{IV}_{\mathrm{A}}$ to form the hexa-acyl lipid A (Figure 1. lipid A form A; Mohan et al., 1994; King et al., 2009). However, unlike in E. coli and S. enterica sv. Typhimurium, the addition of the first core sugar 3-deoxy-D-manno-oct-2-ulosonic acid (Kdo) to the lipid $\mathrm{IV}_{\mathrm{A}}$ is not strictly necessary for the attachment of the secondary acyl groups in P. aeruginosa (Goldman et al., 1988). The non-stoichiometric 2-hydroxylation of the secondary lauroyl group is proposed to be catalyzed by corresponding homologs of S. enterica sv. Typhimurium LpxO (Gibbons et al., 2000, 2008). In P. aeruginosa, two putative LpxO homologs (LpxO1 and LpxO2, encoded by pa4512 and pa1936, respectively) were present; presumably each would hydroxylate one of the two secondary acyl chains (King et al., 2009). A newly identified deacylase enzyme PagL is believed to be involved in the removal of the primary 10:0(3-OH) group at the 3 position of $\mathrm{GlcN}^{\mathrm{I}}$ of the hexa-acylated lipid A (Figure 5, lipid A form A) to form the penta-acylated lipid (Figure 5, lipid A form B), and to convert the hepta-acylated lipid A (Figure 5, form E) to hexa-acylated lipid A (Figure 5, form D) in CF isolates (Ernst et al., 2006). As stated earlier, the lipid A from isolates of patients with acute infection or non-CF chronic infection lacks the secondary $\mathrm{C}_{12}$ acyl chain at GlcN $^{\mathrm{I}}$ (Figure 5, lipid A form C; Ernst et al., 1999, 2003). This could be due to the lack of expression of one of the secondary acyltransferases $l p x L$, or the later removal of the secondary $\mathrm{C}_{12}$ acyl group from lipid A (Figure 5, form A) by a novel deacylase enzyme. The OM palmitoyl transferase protein PagP was originally identified in Salmonella and is responsible for the addition of palmitate to lipid A (Guo et al., 1998). A PagP homolog in $P$. aeruginosa is proposed to catalyze the addition of palmitate to lipid A forms A and B to synthesize lipid A forms E and D that are found in CF patient airway isolates, respectively (Trent, 2004). The hexa-acylated lipid A (form D) could also result from the removal of the primary 10:0 (3-OH) group from the heptaacyl lipid A (form E) by the deacylase enzyme PagL. It is not known which of the two steps, i.e., the addition of palmitate or the removal of the primary 10:0(3-OH), occurs first. However, it has been confirmed that the occurrence of the hepta-acylated lipid A (form E) found only in isolates from CF patients with severe infection was due to the loss of PagL function (Ernst et al., 2006). Although an in vitro assay indicated that a PagP-like enzyme was present in the membranes (Trent, 2004) of P. aeruginosa, to date, no pagP homolog has been identified in the genome (Stover et al., 2000). This could be due to low sequence similarity between these homologs. Similar to Salmonella, the addition of palmitate is regulated by the PhoP-PhoQ two-component regulatory system, as a phoP null mutant of $P$. aeruginosa is not able to synthesize palmitate-modified lipid A under inducing conditions for wildtype strains (such as limited $\mathrm{Mg}^{2+}$; Ernst et al., 1999). The biosynthesis pathway of aminoarabinose and its addition to lipid A has been well characterized in E. coli and S. enterica (reviewed by Trent, 2004 and Bishop, 2005). The gene ugd (also called pmrE) and the pmrHFIJKLM (also referred to as the arnBCADTEF) gene cluster have been identified and characterized to encode enzymes required for the biosynthesis of aminoarabinose as well as its transport across the IM and its ligation to lipid A (Trent, 2004; Bishop, 2005). These homologous genes were identified in a single cluster in the genome of $P$. aeruginosa PAO1 (pa3552-pa3559; Stover et al., 2000). As in E. coli and S. enterica, it was found that both PhoP-PhoQ and another two-component regulatory system PmrA-PmrB are involved in the regulation of the expression of these genes and the addition of aminoarabinose to lipid A (Moskowitz et al., 2004; Moskowitz and Ernst, 2010). Both systems can respond to $\mathrm{Mg}^{2+}$-limiting conditions (Mcphee et al., 2003, 2006); moreover, the PmrA-PmrB system can also respond to the presence of CAMPs including polymyxin B causing activation of the transcription of the pmr gene cluster (Mcphee et al., 2003). 


\section{BIOLOGICAL IMPLICATIONS OF LPS DIVERSITY IN P. AERUGINOSA \\ COLONIZATION AND PERSISTENCE}

Physiological adaptability and metabolic plasticity have long been hallmarks of $P$. aeruginosa survival, traits that were consistent with the annotated genome sequence for strain PAO1, which revealed a wealth of predicted genes involved in various synthesis, assembly, metabolic, regulatory, and pathogenesis paradigms (Stover et al., 2000). This genomic abundance reflects the remarkable versatility of this bacterial species to colonize and persist in diverse niches ranging from different environmental settings to host animal tissues (Wolfgang et al., 2003). While several characteristics of $P$. aeruginosa facilitate initial substratum colonization and later-stage persistence, each is either directly or indirectly affected by variations in the phenotype of the LPS present on the cell surface.

In the aqueous environment, cells of $P$. aeruginosa swim with the aid of a polar flagellum (Feldman et al., 1998), but this mode of motility was impaired in mutants that lacked wildtype smooth LPS due to defects in either core OS biosynthesis, yielding truncated core OS (Lindhout et al., 2009), or ligation of OSA and CPA to the core OS, in the case of a waaL mutant (Abeyrathne et al., 2005). Swarming motility of $P$. aeruginosa cells, which is the process of translocation on semi-solid surfaces dependent on flagella, type IV pili, and rhamnolipid (a wetting agent produced by $P$. aeruginosa; Köhler et al., 2000), was similarly compromised in the aforementioned mutants with truncated core OS. The motility defects in the mutants were found to be a result of changes in cell-surface properties such as cell-to-cell and cell-to-substratum adhesion forces. Both types of adhesive forces became significantly increased in the mutants, as measured by AFM. This is in contrast to the initial thoughts that LPS defects might have somehow affected flagelladriven motility. In fact, when the mutant cells were examined by standard light microscopy, and the swimming speed of individual cells was quantified, no difference could be discerned between the mutant and the wildtype parent strain. The increased adhesive properties retarded all outward motility from the population of $P$. aeruginosa cells (Lindhout et al., 2009).

Biofilm formation is the preferred mode of growth for P. aeruginos a cells clinging to rocks in fluvial streams or surviving in the lungs of CF patients in a chronic infection situation (Hall-Stoodley et al., 2004). Following planktonic growth of P. aeruginosa, attachment to a substratum is a prerequisite for establishing long-term colonization at a particular site to eventually adapt to a biofilm mode of growth. Biofilms are intricate surface-associated bacterial communities that confer survival advantages to the cells residing within and for which flagellar-mediated motility is important for their maturation in P. aeruginosa (O'toole and Kolter, 1998; Klausen et al., 2003). Consistent with the motility defects described above, the same mutants of $P$. aeruginosa lacking complete core OS and the distal CPA and OSA moieties were found to form biofilms with significant differences in mechanical and structural properties when compared to those of wildtype bacteria. This evidence was collected from a variety of quantitative measurement studies to determine changes in ultrastructures, biophysical properties, cell-cell adhesion forces, and viscoelasticity of mutant and wildtype strains using a technique called microbead force spectroscopy (Lau et al., 2009a). Several bacterial strains including knockout mutants disrupted in migA, wapR, and $r m l C$, respectively, and with defined core OS truncation characteristics were compared to their wildtype PAO1 parent strain in these studies. Significant changes were observed in cell mechanical properties among the mutant strains compared to the wildtype PAO1. The functions of migA and $w a p R$ have been described earlier; the $r m l C$ gene is responsible for TDP-L-Rha biosynthesis and hence a $r m l C$ mutant produces a defective core OS truncated at the $\mathrm{Rha}^{\mathrm{A}}$ and $\mathrm{Rha}^{\mathrm{B}}$ residues in the two glycoforms of the core OS (Figure 4). The data from these studies revealed that truncation of core OS enhanced both adhesive and cohesive forces by up to 10-fold, whereas changes in instantaneous elasticity were correlated with the presence of O-Ag. Using AFM to raster-scan bacterial cells in air in contact mode for each of the aforementioned four strains showed differences in the texture of the surface "smoothness." Interestingly, LPS- "smooth" strain wildtype PAO1 with O-Ag exhibits rougher surface topography than rough strains, i.e., the mutant bacterial strains of migA, wapR, and $\mathrm{rmlC}$ (Figure 6). Using confocal laser scanning microscopy to quantify biofilm structural changes in these mutants, we observed that textural parameters varied with adhesion or the inverse of cohesion, while areal and volumetric parameters were linked to adhesion, cohesion, or the balance between them. Microcolonies formed by cells of the wildtype $\mathrm{PAO} 1$ had round perimeters, while the microcolonies formed by the mutant strains had more irregular edges (Figure 7; Lau et al., 2009b). These studies support the importance of O-Ag in the formation of cellular structures and the physiology of $P$. aerugionsa in a biofilm mode of growth. In a study by Ivanov et al. (2011), they showed that changes in the relative proportion of OSA modalities as well as the outright loss of OSA result in reduced virulence of $P$. aeruginosa consistent with diminished surface adhesive forces, further supporting the role of LPS-mediated adhesion in $P$. aeruginosa persistence. The observations made in these recent studies substantiated an earlier report in which rough mutants of P. aeruginosa lacking OSA had an $\mathrm{LD}_{50}$ that was $1000 \mathrm{X}$ higher than that of a wildtype strain in a mouse infection model (Cryz et al., 1984).

\section{PROPERTIES OF P. AERUGINOSA LPS THAT INFLUENCE ITS INTERACTION WITH THE DEFENSE SYSTEMS OF THE HOST}

The genomic stability of $P$. aeruginosa is such that environmental isolates have been found to maintain the potential for pathogenicity through the conservation of numerous virulence-associated genes required for host infection (Wolfgang et al., 2003). Undoubtedly, theses genetic traits contribute to the success of the bacterium as an opportunistic pathogen. In humans, opportunistic infection by $P$. aeruginosa is often seen in patients with varying degrees of compromised host defenses such as those suffering from damaged corneal lenses, cancer, AIDS, severe burn wounds, and CF (Lyczak et al., 2000). As with the more environmental physiological aspects described above, LPS of P. aeruginosa plays multiple key roles in the interaction between the pathogen and the infected host through direct engagement or evasion of innate and adaptive immune system responses.

During the course of infection, it is a general understanding that the humoral adaptive immune response has a lag phase of between 5 days to a week from initial infection detection; in that time period, the innate immune system plays an essential role in engaging and 

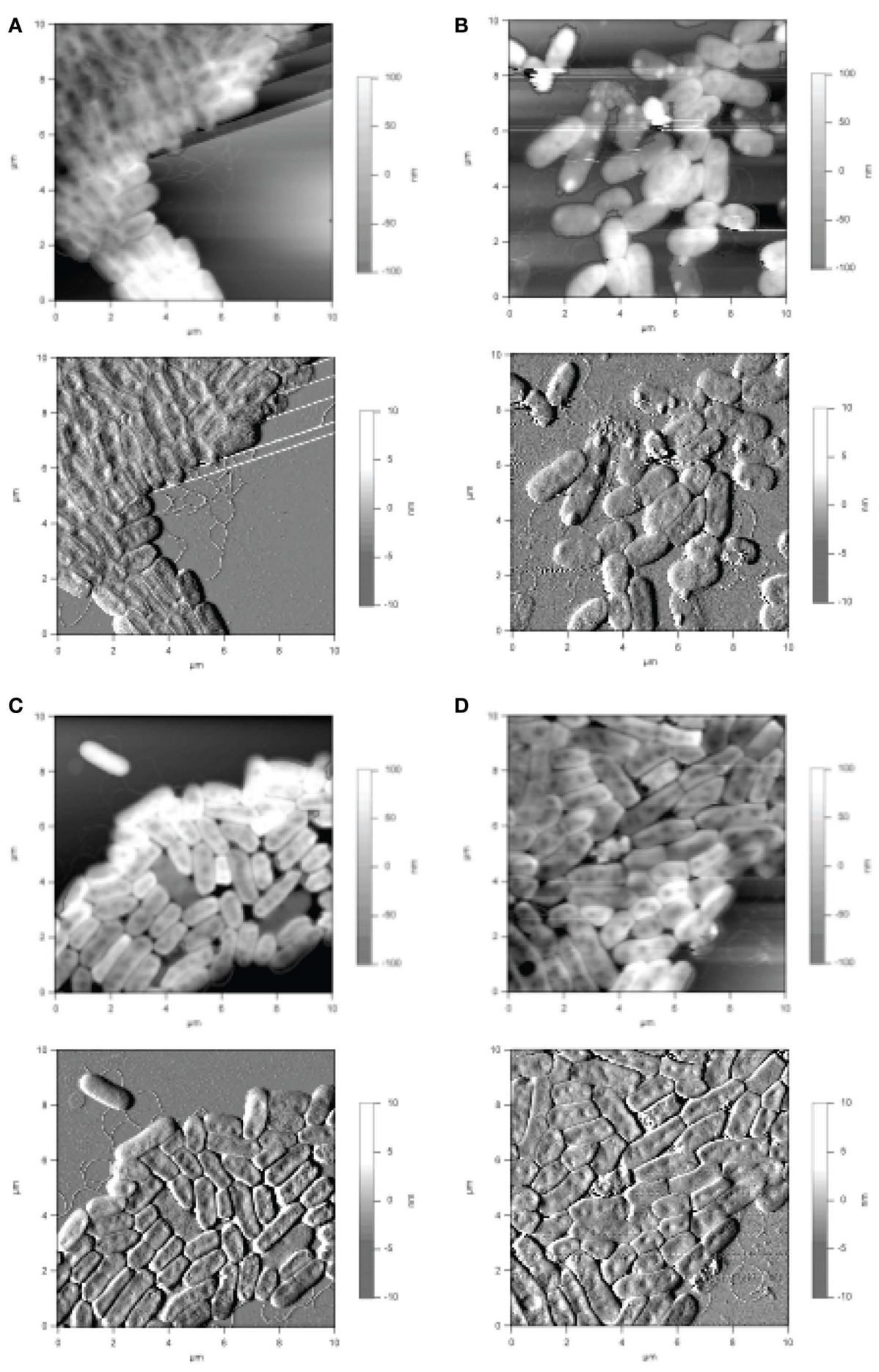

FIGURE 6 | Images obtained from Atomic Force Microscopy analyses of $\boldsymbol{P}$ aeruginosa cells collected in contact mode in air. (A) Strain PAO1; (B) migA mutant; (C) wapR mutant; (D) rm/C mutant. Height images (top panels) are shown with enclosed areas for roughness calculations. Deflection images (bottom panels) reveal more details in cell morphology. The straight lines in (A) are steps in the mica substratum. Reproduced from Lau et al. (2009b), with permission from Copyright Clearance Centre.

managing the infection through a variety of mechanisms. One such mode of action involves the recognition of pathogen-associated molecular patterns (PAMPs) by various pattern recognition receptors in the host (Janeway and Medzhitov, 2002). Arguably, the most widely described reaction of the innate immune system to LPS is that of endotoxicity resulting from recognition of the distal lipid A moiety by the host Toll-like receptor 4 (TLR4) complex, which consists of the TLR4 receptor, the co-receptor component MD-2, and the GPI-linked LPS binding protein CD14 (Da Silva Correia et al., 2001; Hajjar et al., 2002; Palsson-Mcdermott and O'neill, 
A
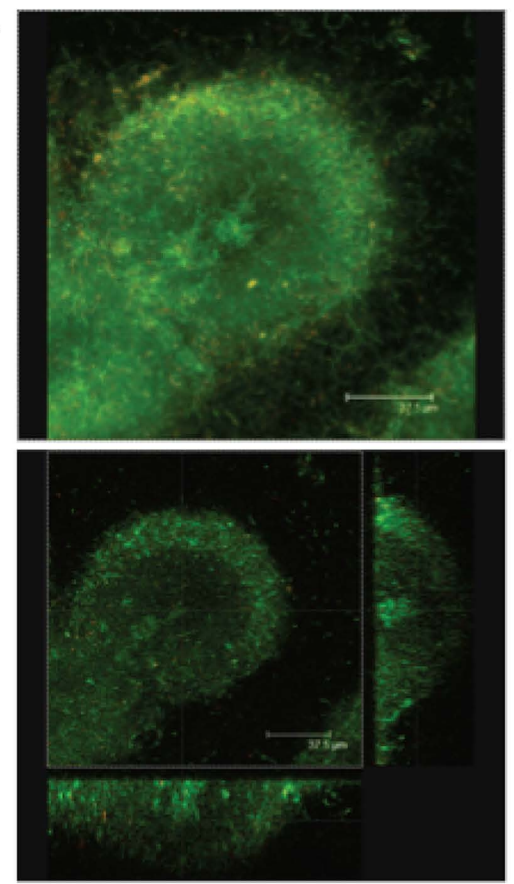

C
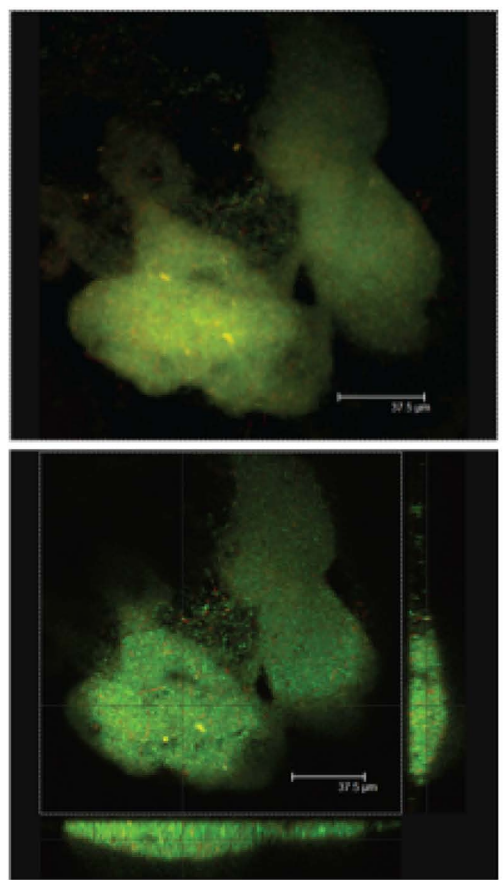

FIGURE 7 | Images from confocal laser scanning microscopy analyses of $P$. aeruginosa cells that illustrate the changes in biofilm structure resulting from truncation in the LPS core in mutant strains as comparing to the wildtype bacteria. Average projections (top panels) and midpoint

2004; Miller et al., 2005). As discussed earlier, during adaptation of $P$. aeruginosa to the CF airway, the normally penta-acylated lipid A of the bacterium (Figure 5, lipid A form B) was modified to a hexa-acylated form (Figure 5, lipid A form D; Ernst et al., 2003), becoming a more robust proinflammatory stimulus mediated by
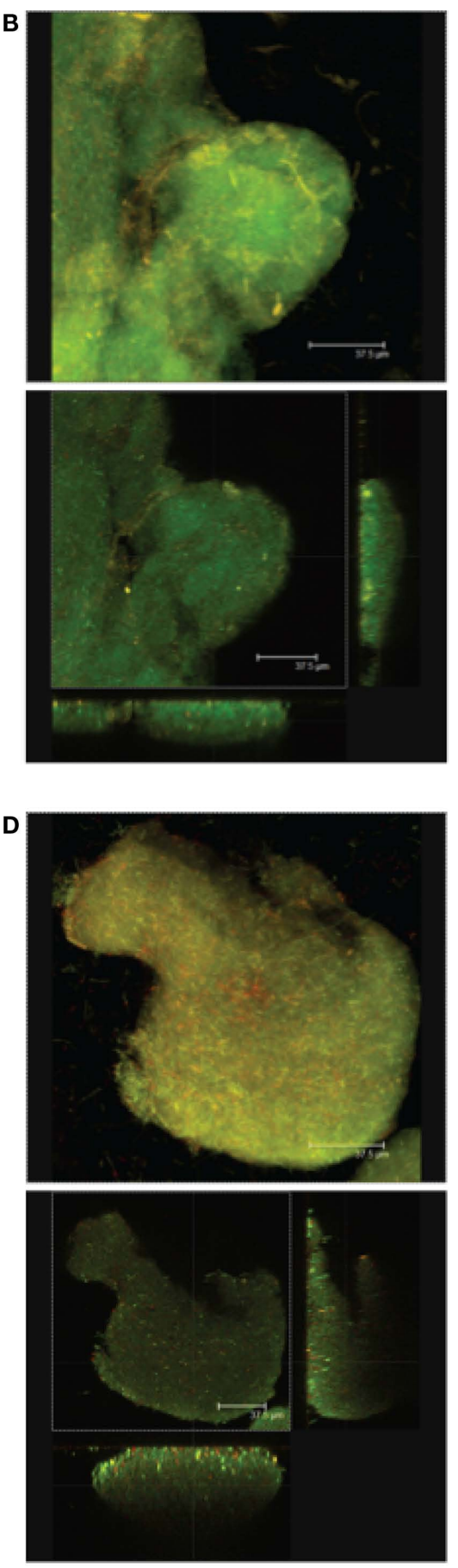

cross sections (bottom panels) of representative microcolonies of (A) wildtype strain PAO1, (B) migA mutant, (C) wapR mutant, and (D) $\mathrm{rm} / \mathrm{C}$ mutant are shown. Reproduced from Lau et al. (2009b), with permission from Copyright Clearance Centre.

the TLR4 complex (Hajjar et al., 2002). In contrast, LPS with pentaacylated lipid A is less potent. Compared to enterobacterial lipid A which has the hexa-acyl form with longer chain fatty acids (C14 versus C10-C12), P. aeruginosa lipid A showed a significantly lower toxicity in an experimental animal model infection (Takada and 
Kotani, 1992; Backhed et al., 2003). On the surface, direct stimulation of the innate immune system by $P$. aeruginosa would appear to be a curious survival strategy for a pathogen that establishes chronic infections in CF patients; however, this strongly points to an as-yet-to-be-determined survival advantage for $P$. aeruginosa conferred by constant inflammation of the airway epithelium. Conversely, this sequence of proinflammatory responses has been recognized as a direct contributing factor to the gradual deterioration of lung capacity in CF patients with P. aeruginosa infection (Hoiby et al., 2010).

Modifications to the lipid A domain of LPS may also confer other survival advantages. The host innate immune system produces a wide range of CAMPs, and some of them (such as cecropin and human defensin) directly interact with bacterial membranes (Hancock and Diamond, 2000). The addition of positively charged aminoarabinose to the phosphate groups of lipid A reduces the permeability of the OM or the affinity of lipid A for those CAMPs, and has clearly been shown to promote $P$. aeruginosa resistance to CAMPs; thus, such modifications may increase bacterial survival rates during host colonization (Ernst et al., 1999, 2007; Macfarlane et al., 2000; Moskowitz et al., 2004; Trent, 2004).

The principal genetic defect resulting in altered physiology of patients with CF is a loss of function of the CF transmembrane conductance regulator (CFTR), a chloride ion channel important for maintaining the optimal viscosity of mucus membranes. Impaired CFTR function results in the production of mucus that is highly viscous, creating an ecological niche in the respiratory tract similar to a biofilm matrix, ideal for colonization by $P$. aeruginosa (Gibson et al., 2003). However, in addition to the increased viscosity of the lung environment, a deficiency in binding of $P$. aeruginosa by CFTR also contributes to pathogenesis. Uptake of bacteria by airway epithelial cells has been implicated as a key mechanism for clearance of $P$. aeruginosa and CFTR was shown to play a role as a receptor and contribute to epithelial internalization (Bajmoczi et al., 2009). Murine cells lacking recombinant human CFTR, as well as those expressing the predominant $\Delta$ F508 CFTR mutant, displayed significant impairment in the binding and endocytosis of $P$. aeruginosa, compared to expression of the wildtype human protein (Pier et al., 1997), with the core OS portion of the LPS molecule of the bacterium implicated as the ligand responsible for uptake (Pier et al., 1996). As such, in individuals with wildtype CFTR, clearance of $P$. aeruginosa is mediated by uptake of the infecting bacteria via binding to CFTR and subsequent internalization. However, studies of experimental eye infections demonstrated that CFTR-mediated internalization of $P$. aeruginosa by corneal epithelial cells is essential to the development of keratitis (Zaidi et al., 1999), a potentially severe infection of the ocular lens often developed by individuals that frequently wear contact lenses (Robertson et al., 2007). In this scenario, the core OS-mediated interaction of CFTR with P. aeruginosa is detrimental to the human host rather than beneficial.

Activation of the complement cascade, which is comprised of more than 30 serum and cell-surface proteins, is another response of the innate immune system essential to combating infection. Three known mechanisms lead to activation of the complement system, namely, the classical (CCP), alternative (ACP), and mannan-binding lectin (MBL) pathways, each of which results in activation of $\mathrm{C} 3$ to yield $\mathrm{C} 3 \mathrm{~b}$; in turn, this can lead to opsonization of pathogens and engulfment by phagocytes or surface deposition of complement components C5b, C6, C7, C8, and C9 to form the lytic membrane-attack complex (Dunkelberger and Song, 2010). In a murine model of $P$. aeruginosa-induced pneumonia, C3-deficient mice displayed higher mortality rates than $\mathrm{C} 3$-expressing mice. The C3-deficient mortality rates were similar to those observed for mice deficient in ACP-specific factor B, but not for mice deficient in CCP- and MBL-specific C4, indicating a critical role for the ACP in controlling initial $P$. aeruginosa pulmonary infection. Phagocytic cells from both the C3-expressing and C3-deficient mice displayed a reduced capacity in vitro to bind and take up $P$. aeruginosa in the presence of C3-deficient serum compared to C3-containing serum, suggesting that phagocytic clearance of the bacterium via C3-mediated opsonization constitutes a part of the protection afforded by the ACP against $P$. aeruginosa infection(Mueller-Ortiz et al., 2004).

Clinical isolates of $P$. aeruginosa from CF patients, deficient in long-chain $\mathrm{O}$-Ag production, were found to be sensitive to pooled normal human serum (PNHS) when compared to subcultured derivatives of the parental strains with restored O-Ag chain biosynthesis, which were found to be serum resistant (Schiller et al., 1984). The same derivative strains with restored O-Ag biosynthesis were subsequently shown to activate (i.e., consume) more complement from PNHS per bacterial organism than their O-Ag-deficient parental counterparts. Serum-sensitive strains were observed to accumulate more C3 than serum-resistant strains, with the $\mathrm{C} 3$ accumulation also occurring more rapidly in the former; both of these phenotypes were reduced upon prior treatment of the PNHS with ethylene glycol tetraacetic acid (EGTA, which blocks the CCP), suggesting that the CCP is important for maximal deposition of C3. Analysis of the form of $\mathrm{C} 3$ deposited on the surface of the various serum-sensitive and serum-resistant strains indicated equivalent amounts of $\mathrm{C} 3 \mathrm{~b}$ and $\mathrm{iC} 3 \mathrm{~b}$ (proteolytically inactivated $\mathrm{C} 3 \mathrm{~b}$ ) in the former, while the latter contained mostly iC3b (Schiller et al., 1989). Taken together, these results indicate that complement-mediated responses to $P$. aeruginosa are an important part of the infection resolution mechanism, which is directly affected by the presence of O-Ag on the bacterial surface.

Sugar-binding proteins known as lectins, of which there are several classes, are also known to play a role in the innate immune response to $P$. aeruginosa infection. Surfactant proteins A (SPA) and D (SP-D) are part of the calcium-dependent, collagenous C-type lectin family, containing carbohydrate-recognition domains. In the lung, they are secreted into the mucus lining the epithelium wherein they facilitate clearance of microbial pathogens via agglutination, neutralization, and opsonization (Holmskov et al., 2003). SP-A and SP-D have been shown to bind both rough and smooth strains of P. aeruginosa (Bufler et al., 2003), with SP-D interacting specifically with LPS (Kishore et al., 1996); incidentally, both surfactant proteins have been shown to be important for clearance of P. aeruginosa (Levine et al., 1998; Mariencheck et al., 1999; Restrepo et al., 1999; Ni et al., 2005) but are present at reduced levels in the lungs of CF patients (Postle et al., 1999). In a separate investigation, the signal from biotin-labeled LPS from 
$P$. aeruginosa was shown to overlap with that obtained with antibodies against the S-type lectin galectin-3 via Western blotting of human corneal epithelial proteins, suggesting binding of the LPS by galectin-3. Additionally, pretreatment of scarified corneas in whole-eye culture with mAbs against either the outer core OS from $P$. aeruginosa or galectin-3 was found to inhibit binding of the bacterium to the cornea (Gupta et al., 1997). Coupled with the importance of SP-A and SP-D described above, the capacity of galectin-3 in binding of $P$. aeruginosa indicates a significant role for LPS-dependent lectin-mediated clearance of $P$. aeruginosa infection via the innate immune response.

It has been demonstrated that the type III secretion system (T3SS) of the bacterium mediates direct virulence-promoting primary interactions between $P$. aeruginosa and the host. This pathogenesis mechanism involves the highly regulated contactdependent insertion of a needle-like injector assembly into a host cell by the surface-associated bacterium, followed by the extrusion of four principal effector proteins (ExoS, T, U, Y) from the bacterium directly into the cytosol of the host cell. These type III effector proteins display a wide range of substrate specificities and in turn perturb a diverse range of host cell functions (Hauser, 2009). Intriguingly, upon comparison of isogenic LPS mutants to wildtype $P$. aeruginosa, the relative levels of expression of exoS and exoT (encoding effectors) exsA (encoding the positive T3SS regulator), and $p c r V$ (encoding the injection-facilitation component) displayed marked increases in the absence of OSA. Even more pronounced increases in gene expression were observed in the simultaneous absence of OSA and CPA, suggesting a strong regulatory association between the presence/absence of capped core OS and T3SS effector expression (Augustin et al., 2007). Intracellularly, the production of ExoS and PcrV were found to be reflective of upregulated gene expression. $P$. aeruginosa mutants defective in OSA and CPA were also found to confer increased cytotoxicity in vitro and in vivo in lung epithelial cells and a murine model of infection, respectively (Augustin et al., 2007), indicating that the presence of O-Ag is an important factor contributing to the regulation and expression of T3SS effectors.

Notwithstanding either innate immune system interplay or T3SS activity, the host-pathogen interaction dynamic is also applicable with $P$. aeruginosa as the host and bacteriophage as the infectious agents. To date, multiple motifs on the LPS molecule of $P$. aeruginosa have been identified as receptors for various bacteriophages. As discussed earlier, bacteriophage A7 was found to bind and hydrolyze the D-Rha of CPA in a P. aeruginosa mutant devoid of OSA (Rivera et al., 1992). In addition, specificity for OSA has also been identified through examination of bacteriophage D3; lysogenization with the phage resulted in a loss of adsorption with the same phage during subsequent infection cycles (Holloway and Cooper, 1962), a phenotypic alteration later identified to be a result of acetyl-group addition at the D-Fuc residue as well as alteration of the linkage stereochemistry between OSA repeat units from $\alpha 1 \rightarrow 4$ to $\beta 1 \rightarrow 4$, resulting in serotype conversion. Lysogenization by D3 also impeded the binding ability of the unrelated LPSspecific phage E79 (Kuzio and Kropinski, 1983). The core OS of the bacterium is not only an important ligand for interaction with eukaryotic cells, but it is also a receptor for bacteriophages. Phages $\varphi \mathrm{CTX}, \varphi \mathrm{PLS} 27, \mathrm{E} 79$, and H22 have all been shown to recognize the core OS domain of $P$. aeruginosa LPS (Meadow and Wells, 1978; Jarrell and Kropinski, 1981b; Temple et al., 1986; Yokota et al., 1994).

Analogous to the binding of $P$. aeruginosa by bacteriophage is the interaction of pyocins with the surface of the bacterium. Pyocins are chromosomally encoded by over $90 \%$ of $P$. aeruginosa strains and are inducible upon treatment with certain mutagenic agents. Depending on the type of pyocins, which might behave like lytic proteins or phage-like particles, they can disrupt the membranes of both related and unrelated bacteria, but which normally have no effect on the host strain (Michel-Briand and Baysse, 2002). Three principal pyocin types have been described, with the R-type (rod-shaped) pyocins closely resembling the contractile tails of bacteriophage. Specifically, R-type pyocins are related to $\varphi$ CTX bacteriophages (Hayashi et al., 1994), with core OS serving as a receptor. Five subtypes of R-type pyocins (R1-R5) have been described, each with different killing spectra. Using a collection of well-defined LPS-deficient $P$. aeruginosa knockout mutants generated by our group, the $\mathrm{Rha}^{\mathrm{A}}$, Glc ${ }^{\mathrm{II}}$, and $\mathrm{Glc} / \mathrm{Glc}^{\mathrm{III}}$ core sugars (Figure 5) were identified as receptors for R1, R2, and R5 R-type pyocins, respectively. Therefore, spontaneous truncations of the core OS provide resistance to some of the R pyocins. The presence of OSA on the surface of $P$. aeruginosa was demonstrated to provide a "shield" against pyocin-mediated killing (Köhler et al., 2010).

\section{TREATMENT AND PREVENTION OF INFECTION}

Upon infection with $P$. aeruginosa, leading treatment regimens often involve doses of antibiotics such as oral ciprofloxacin, or aerosolized drugs including TOBI $^{\circledast}$ (inhaled tobramycin therapeutic), or colymycin (inhaled colistin-lysin) that are currently being used to treat CF patients nowadays (Anderson, 2010). Tobramycin belongs to the family of aminoglycosides that inhibits bacterial protein biosynthesis via irreversible binding to the $30 \mathrm{~S}$ bacterial ribosome (Edson and Terrell, 1999). Aminoglycosides such as gentamicin have also been shown to disrupt the cell envelope of $P$. aeruginosa (Martin and Beveridge, 1986; Walker and Beveridge, 1988), leading to lysis of the bacterium (Kadurugamuwa et al., 1993a). Irrespective of its mechanism of bactericidal activity, the initial event in gentamicin-mediated treatment of infection involves ionic binding of the drug to the surface of P. aeruginosa. However, comparison of a wildtype strain with isogenic mutants lacking various LPS glycoforms indicated a higher affinity of OMs containing OSA for gentamicin. Furthermore, OSA-expressing strains were more susceptible to killing via gentamicin treatment, with viability reduced almost $50 \%$ in strains simultaneously expressing OSA and CPA as a result of higher antibiotic binding than in any other strain (Kadurugamuwa et al., 1993b). The importance of OSA in gentamicin binding has direct implications for the treatment of CF patients, as chronic $P$. aeruginosa isolates often lose the ability to synthesize OSA, while LPS capped with CPA is maintained (Hancock et al., 1983; Lam et al., 1989).

Given the ability of various phages to specifically and selectively target their respective host bacterium, combined with their overall lack of eukaryotic epitope recognition, the use of phage to control bacterial infection is once again gaining attention in the medical community after a prolonged period of research dormancy in the field (Hanlon, 2007) This is of particular interest in light of the 
continued development of widespread resistance to antibiotics, including isolates of $P$. aeruginosa, a bacterium already known to possess high intrinsic antibiotic resistance. As such, with a range of $P$. aeruginosa-specific bacteriophages identified (Ceyssens and Lavigne, 2010), phage therapy could serve as an alternative or complementary method to the treatment and management of infections with this bacterium. One such example is the recently identified LPS-specific phage JG024 which was found to efficiently lyse a wide range of environmental and clinical isolates of $P$. aeruginosa (Garbe et al., 2010).

Rather than intervention through therapeutic measures after an infection has occurred, researchers have pursued prevention of $P$. aeruginosa colonization through the use of immunogenic vaccines to foster sustained adaptive immunity (Stanislavsky and Lam, 1997). Various vaccine formulations have been tested in a range of healthy and compromised individuals, using mixtures of LPS from different serotypes, different LPS components, immunogenic toxins conjugated to LPS components, and inactivated whole-cell preparations, all traditionally administered via injection (Stanislavsky and Lam, 1997; Sedlak-Weinstein et al., 2005). While certain vaccine trials involving whole-molecule LPS preparations have yielded increased anti-LPS antibody titres, most LPS vaccines have been characterized by various toxic side effects, yielding inconsistent results with varying degrees of sustained protection (Sedlak-Weinstein et al., 2005). Furthermore, certain instances of non-Pseudomonas microbe replacement have also been identified following testing of LPS vaccines (Pennington et al., 1975; Jones et al., 1979). To circumvent issues of pyrogenicity associated with purified LPS used for injection, lipid A-core OS from $P$. aeruginosa (and three other species) was reconstituted in liposomes and used to immunize rabbits, resulting in a welltolerated vaccine that induced the production of cross-reactive anti-core OS antibodies against a large panel of pathogenic Gram-negative bacteria expressing both rough and smooth LPS (Bennett-Guerrero et al., 2000); this same liposomal formulation was later demonstrated to reduce the induction of TNF- $\alpha$ production in vitro when compared to the equivalent amounts of the purified LPS constituents (Erridge et al., 2002). As such, liposomal reconstitution may provide a means of reducing the endotoxic effects of LPS vaccine while still maintaining their protective efficacy.

In comparison to immunization with whole-molecule LPS, OSA vaccines are well tolerated. Correlation between the length of the OSA polymer and the production of protective antibodies was demonstrated in mice, with OSA containing over 18 repeat units inducing 50- to 100-fold increases (Macintyre et al., 1986). In CF patients not previously infected by $P$. aeruginosa, immunization with an octavalent OSA vaccine conjugated to exotoxin A was found to elicit high levels of anti-OSA antibodies in the serum (Lang et al., 1995), a trend sustained with yearly immunizations for a decade (Zuercher et al., 2006). These regular immunizations with the octavalent OSA-exotoxin A conjugate vaccine were found to delay the occurrence of colonization and reduce the frequency of chronic infection in young CF patients (Lang et al., 2004), demonstrating promise as a potential commercialized vaccine to prevent $P$. aeruginosa infection. Another method to induce protective immunity against $P$. aeruginosa has been through the genera- tion of recombinant immunogens involving the OSA from certain serotypes. Heterologous expression of P. aeruginosa O11 OSA in an attenuated strain of $S$. enterica sv. Typhimurium, followed by intranasal immunization, resulted in the production of OSA-specific antibodies in the serum of immunized mice. Complete protection with the immunization was also provided against respiratory challenges until 6 months post-vaccination as well as against infection from a burn wound, while only partial protection was provided against corneal infection (Digiandomenico et al., 2007). This is a novel method for the stimulation of adaptive immunity against $P$. aeruginosa. However, despite the data from some of these studies demonstrating efficacy of the vaccine formulations in animal models, obvious hurdles must be overcome before the vaccines can be administered to CF patients. One of these would be the development of an effective and accurate diagnostic method to determine whether or not a young CF patient has been colonized by $P$. aeruginosa. Infected patients produce high amounts of antibodies against LPS. Therefore, administering a vaccine to a patient who has previously been colonized by $P$. aeruginosa can have deleterious effects due to the formation of immune complexes between specific antibodies against $P$. aeruginosa surface antigens, such as LPS, and the vaccine antigens. The presence of these immune complexes could lead to serum sickness. Ultimately, the continued pursuit of an effective anti- $P$. aeruginosa vaccine involving LPS (whole or in part) is an important avenue of research that will undoubtedly benefit millions of people suffering from a range of medical conditions.

Considering all of the aforementioned biological implications of LPS diversity in P. aeruginosa, it is indisputable that the bacterium follows a very complex infection dynamic, involving a multitude of simultaneous interactions with the host, many of which it can exploit to further pathogenesis and its continued survival upon infection; yet a majority of these virulence mechanisms are affected, either directly or indirectly, by the LPS of the pathogen. As such, continued research into the biosynthesis and assembly of this important cell-surface virulence factor is essential to clearly understanding the colonization process and eventually controlling or inhibiting infection by $P$. aeruginosa.

\section{CONCLUSION}

In this review, we have provided a comprehensive account of the genetics for the biosynthesis of each of the three regions of $P$. aeruginosa LPS. We have also provided a critical review of the information in the literature pertaining to knowledge of how the variation in producing each region of the LPS can impart diversity to this species. External factors such as temperate bacteriophages that recognize LPS epitopes as receptors, followed by internalization and propagating the viral life cycle, also influence diversity of LPS. All of these different factors account for the heterogeneity of $P$. aeruginosa, not only of the chain length of the O-Ag, but also of the chemical make up that accounts for the different serotypes. We close out the discussion by addressing the importance of LPS in host-pathogen interactions and the strategies that researchers use to target this cell-surface glycolipid to develop effective vaccines or novel antimicrobial interventions against $P$. aeruginosa infections. Suggestions for future research have been integrated throughout the various sections. 


\section{ACKNOWLEDGMENTS}

The authors thank Dr. Peter Lau for providing confocal and atomic force microscopy images. Research in the laboratory of Joseph S. Lam is funded by operating grants from Cystic Fibrosis Canada (CFC) and the Canadian Institutes of Health Research (CIHR; no. MOP-14687). Joseph S. Lam is the holder

\section{REFERENCES}

Abeyrathne, P. D., Daniels, C., Poon, K. K., Matewish, M. J., and Lam, J. S. (2005). Functional characterization of WaaL, a ligase associated with linking $\mathrm{O}$-antigen polysaccharide to the core of Pseudomonas aeruginosa lipopolysaccharide. J. Bacteriol. 187, 3002-3012.

Abeyrathne, P. D., and Lam, J. S. (2007). WaaL of Pseudomonas aeruginosa utilizes ATP in in vitro ligation of $\mathrm{O}$ antigen onto lipid A-core. Mol. Microbiol. 65, 1345-1359.

Anderson, P. (2010). Emerging therapies in cystic fibrosis. Ther. Adv. Respir. Dis. 4, 177-185.

Arsenault, T. L., Hughes, D. W., Maclean, D. B., Szarek, W. A., Kropinski, A. M. B., and Lam, J. S. (1991). Structural studies on the polysaccharide portion of 'A-band' lipopolysaccharide from a mutant (AK14O1) of Pseudomonas aeruginosa PAO1. Can. J. Chem. 69, 1273-1280.

Augustin, D. K., Song, Y., Baek, M.S., Sawa, Y., Singh, G., Taylor, B., Rubio-Mills, A., Flanagan, J. L., Wiener-Kronish, J. P., and Lynch, S. V. (2007). Presence or absence of lipopolysaccharide $\mathrm{O}$ antigens affects type III secretion by Pseudomonas aeruginosa. J. Bacteriol. 189, 2203-2209.

Backhed, F., Normark, S., Schweda, E. K., Oscarson, S., and Richter-Dahlfors, A. (2003). Structural requirements for TLR4-mediated LPS signalling: a biological role for LPS modifications. Microbes Infect. 5, 1057-1063.

Bagdian, G., Luderitz, O., and Staub, A. M. (1966). Immunochemical studies on Salmonella: XI chemical modification correlated with conversion of group B Salmonella by bacteriophage 27. Ann. N. Y. Acad. Sci. 133, 405-424.

Bajmoczi, M., Gadjeva, M., Alper, S. L., Pier, G. B., and Golan, D. E. (2009). Cystic fibrosis transmembrane conductance regulator and caveolin-1 regulate epithelial cell internalization of Pseudomonas aeruginosa. Am. J. Physiol. Cell Physiol. 297, C263-C277.

Beckmann, F., Moll, H., Jager, K. E., and Zahringer, U. (1995). Preliminary communication 7-O-carbamoyl-Lglycero-D-manno-heptose: a new core constituent in the lipopolysaccharide of Pseudomonas aeruginosa. Carbohydr. Res. 267, C3-C7.
Bedoux, G., Vallee-Rehel, K., Kooistra, O., Zahringer, U., and Haras, D. (2004). Lipid A components from Pseudomonas aeruginosa PAO1 (serotype O5) and mutant strains investigated by electrospray ionization ion-trap mass spectrometry. J. Mass. Spectrom. 39, 505-513.

Belanger, M., Burrows, L. L., and Lam, J. S. (1999). Functional analysis of genes responsible for the synthesis of the B-band O-antigen of Pseudomonas aeruginosa serotype O6 lipopolysaccharide. Microbiology 145, 3505-3521.

Bennett-Guerrero, E., Mcintosh, T. J. Barclay, G. R., Snyder, D. S., Gibbs, R. J., Mythen, M. G., and Poxton, I. R. (2000). Preparation and preclinical evaluation of a novel liposomal complete-core lipopolysaccharide vaccine. Infect. Immun. 68, 6202-6208.

Bhat, R., Marx, A., Galanos, C., and Conrad, R.S. (1990). Structural studies of lipid A from Pseudomonas aeruginosa PAO1: occurrence of 4-amino4-deoxyarabinose. J. Bacteriol. 172, 6631-6636.

Bishop, R. E. (2005). Fundamentals of endotoxin structure and function. Contrib. Microbiol. 12, 1-27.

Bufler, P., Schmidt, B., Schikor, D. Bauernfeind, A., Crouch, E. C., and Griese, M. (2003). Surfactant protein A and $\mathrm{D}$ differently regulate the immune response to nonmucoid Pseudomonas aeruginosa and its lipopolysaccharide. Am. J. Respir. Cell Mol. Biol. 28, 249-256.

Burrows, L. L., Charter, D. F., and Lam, J.S. (1996). Molecular characterization of the Pseudomonas aeruginosa serotype O5 (PAO1) B-band lipopolysaccharide gene cluster. Mol. Microbiol. 22, 481-495.

Burrows, L. L., Chow, D., and Lam, J. S. (1997). Pseudomonas aeruginosa $\mathrm{B}$-band $\mathrm{O}$-antigen chain length is modulated by Wzz (Ro1). J. Bacteriol. 179, 1482-1489.

Burrows, L. L., and Lam, J. S. (1999). Effect of wzx (rfbX) mutations on A-band and B-band lipopolysaccharide biosynthesis in Pseudomonas aeruginosa O5. J. Bacteriol. 181, 973-980.

Bystrova, O. V., Knirel, Y. A., Lindner, B., Kocharova, N. A., Kondakova, A. N., Zahringer, U., and Pier, G. B. (2006). Structures of the core oligosaccharide and $\mathrm{O}$-units in the $\mathrm{R}$ - and SR-type lipopolysaccharides of reference

of a Canada Research Chair in Cystic Fibrosis and Microbial Glycobiology. Salim T. Islam is the recipient of a CIHR Frederick Banting and Charles Best Canada Graduate Scholarship doctoral award and a CIHR Michael Smith Foreign Study award. Youai Hao and Dana Kocíncová are recipients of CFC postdoctoral fellowship awards.

strains of Pseudomonas aeruginosa O-serogroups. FEMS Immunol. Med. Microbiol. 46, 85-99.

Cavenagh, M. M., and Miller, R. V. (1986). Specialized transduction of Pseudomonas aeruginosa PAO by bacteriophage D3. J. Bacteriol. 165, 448-452.

Cerantola, S., and Montrozier, H. (1997). Structural elucidation of two polysaccharides present in the lipopolysaccharide of a clinical isolate of Burkholderia cepacia. Eur. J. Biochem. 246, 360-366.

Ceyssens, P.-J., and Lavigne, R. (2010). Bacteriophages of Pseudomonas. Future Microbiol. 5, 1041-1055.

Choudhury, B., Carlson, R. W., and Goldberg, J. B. (2005). The structure of the lipopolysaccharide from a galU mutant of Pseudomonas aeruginosa serogroup-O11. Carbohydr. Res. 340 2761-2772.

Choudhury, B., Carlson, R. W., and Goldberg, J. B. (2008). Characterization of the lipopolysaccharide from a wbjE mutant of the serogroup O11 Pseudomonas aeruginosa strain, PA103. Carbohydr. Res. 343, 238-248.

Creuzenet, C., and Lam, J. S. (2001). Topological and functional characterization of $\mathrm{WbpM}$, an inner membrane UDP-GlcNAc C6 dehydratase essential for lipopolysaccharide biosynthesis in Pseudomonas aeruginosa. Mol. Microbiol. 41, 1295-1310.

Cryz, S. J., Jr., Pitt, T. L., Furer, E., and Germanier, R. (1984). Role of lipopolysaccharide in virulence of Pseudomonas aeruginosa. Infect. Immun. 44, 508-513.

Currie, H. L., Lightfoot, J., and Lam, J. S. (1995). Prevalence of gca, a gene involved in synthesis of A-band common antigen polysaccharide in Pseudomonas aeruginosa. Clin. Diagn. Lab. Immunol. 2, 554-562.

Da Silva Correia, J., Soldau, K., Christen, U., Tobias, P. S., and Ulevitch, R. J. (2001). Lipopolysaccharide is in close proximity to each of the proteins in its membrane receptor complex. Transfer from CD14 to TLR4 and MD-2. J. Biol. Chem. 276, 21129-21135.

Daniels, C., Griffiths, C., Cowles, B., and Lam, J. S. (2002). Pseudomonas aeruginosa $\mathrm{O}$-antigen chain length is determined before ligation to lipid A core. Environ. Microbiol. 4, 883-897.
Dasgupta, T., De Kievit, T. R., Masoud, H., Altman, E., Richards, J. C., Sadovskaya, I., Speert, D. P., and Lam, J. S. (1994). Characterization of lipopolysaccharide-deficient mutants of Pseudomonas aeruginosa derived from serotypes O3, O5, and O6. Infect. Immun. 62, 809-817.

De Kievit, T. R., Dasgupta, T., Schweizer, H., and Lam, J. S. (1995). Molecular cloning and characterization of the rfo gene of Pseudomonas aeruginosa (serotype O5). Mol. Microbiol. 16, 565-574.

De Kievit, T. R., and Lam, J. S. (1994). Monoclonal antibodies that distinguish inner core, outer core, and lipid A regions of Pseudomonas aeruginosa lipopolysaccharide. J. Bacteriol. 176, 7129-7139.

De Kievit, T. R., and Lam, J. S. (1997). Isolation and characterization of two genes, waaC ( $\mathrm{rfaC}$ ) and waaF (rfaF), involved in Pseudomonas aeruginosa serotype $\mathrm{O} 5$ inner-core biosynthesis. J. Bacteriol. 179, 3451-3457.

Dean, C. R., Franklund, C. V., Retief, J. D., Coyne, M. J. Jr., Hatano, K., Evans, D. J., Pier, G. B., and Goldberg, J. B. (1999). Characterization of the serogroup O11 O-antigen locus of Pseudomonas aeruginosa PA103. J. Bacteriol. 181, 4275-4284.

Dean, C. R., and Goldberg, J. B. (2000). The wbpM gene in Pseudomonas aeruginosa serogroup $\mathrm{O} 17$ resides on a cryptic copy of the serogroup O11 O antigen gene locus. FEMS Microbiol. Lett. 187, 59-63.

Digiandomenico, A., Rao, J., Harcher, K., Zaidi, T. S., Gardner, J., Neely, A. N., Pier, G. B., and Goldberg, J. B. (2007). Intranasal immunization with heterologously expressed polysaccharide protects against multiple Pseudomonas aeruginosa infections. Proc. Natl. Acad. Sci. U.S.A. 104, 4624-4629.

Dotson, G. D., Kaltashov, I. A., Cotter, R J., and Raetz, C. R. (1998). Expression cloning of a Pseudomonas gene encoding a hydroxydecanoyl-acyl carrier protein-dependent UDP-GlcNAc acyltransferase. J. Bacteriol. 180, 330-337.

Dunkelberger, J. R., and Song, W. C. (2010). Complement and its role in innate and adaptive immune responses. Cell Res. 20, 34-50.

Edson, R. S., and Terrell, C. L. (1999). The aminoglycosides. Mayo Clin. Proc. 74, 519-528. 
Ernst, R. K., Adams, K. N., Moskowitz, S. M., Kraig, G. M., Kawasaki, K., Stead, C. M., Trent, M. S., and Miller, S. I. (2006). The Pseudomonas aeruginosa lipid A deacylase: selection for expression and loss within the cystic fibrosis airway. J. Bacteriol. 188, 191-201.

Ernst, R. K., Hajjar, A. M., Tsai, J. H., Moskowitz, S. M., Wilson, C. B., and Miller, S. I. (2003). Pseudomonas aeruginosa lipid A diversity and its recognition by Toll-like receptor $4 . \mathrm{J}$. Endotoxin. Res. 9, 395-400.

Ernst, R. K., Moskowitz, S. M., Emerson, J. C., Kraig, G. M., Adams, K. N., Harvey, M. D., Ramsey, B., Speert, D. P., Burns, J. L., and Miller, S. I. (2007). Unique lipid A modifications in Pseudomonas aeruginosa isolated from the airways of patients with cystic fibrosis. J. Infect. Dis. 196, 1088-1092.

Ernst, R. K., Yi, E. C., Guo, L., Lim, K. B., Burns, J. L., Hackett, M., and Miller, S. I. (1999). Specific lipopolysaccharide found in cystic fibrosis airway Pseudomonas aeruginosa. Science 286, 1561-1565.

Erridge, C., Stewart, J., Bennett-Guerrero, E., Mcintosh, T. J., and Poxton, I. R. (2002). The biological activity of a liposomal complete core lipopolysaccharide vaccine. J. Endotoxin. Res. 8, 39-46.

Feldman, M., Bryan, R., Rajan, S., Scheffler, L., Brunnert, S., Tang, H., and Prince, A. (1998). Role of flagella in pathogenesis of Pseudomonas aeruginosa pulmonary infection. Infect. Immun. 66, 43-51.

Fuqua, W. C., Winans, S. C., and Greenberg, E. P. (1994). Quorum sensing in bacteria: the LuxR-LuxI family of cell density-responsive transcriptional regulators. J. Bacteriol. 176, 269-275.

Garbe, J., Wesche, A., Bunk, B., Kazmierczak, M., Selezska, K., Rohde, C., Sikorski, J., Rohde, M., Jahn, D., and Schobert, M. (2010). Characterization of JG024, a Pseudomonas aeruginosa PB1-like broad host range phage under simulated infection conditions. BMC Microbiol. 10, 301. doi: 10.1186/1471-2180-10-301

Ghanei, H., Abeyrathne, P. D., and Lam, J. S. (2007). Biochemical characterization of MsbA from Pseudomonas aeruginosa. J. Biol. Chem. 282, 26939-26947.

Gibbons, H. S., Lin, S., Cotter, R. J., and Raetz, C. R. (2000). Oxygen requirement for the biosynthesis of the $S$-2-hydroxymyristate moiety in Salmonella typhimurium lipid A. Function of LpxO, A new Fe2+l alpha-ketoglutarate-dependent dioxygenase homologue. J. Biol. Chem. 275, 32940-32949.
Gibbons, H. S., Reynolds, C. M., Guan, Z., and Raetz, C. R. (2008). An inner membrane dioxygenase that generates the 2-hydroxymyristate moiety of Salmonella lipid A. Biochemistry 47, 2814-2825.

Gibson, R. L., Burns, J. L., and Ramsey, B. W. (2003). Pathophysiology and management of pulmonary infections in cystic fibrosis. Am. J. Respir. Crit. Care Med. 168, 918-951.

Goldman, R.C.,Doran, C.C., Kadam, S. K., and Capobianco, J. O. (1988). Lipid A precursor from Pseudomonas aeruginosa is completely acylated prior to addition of 3-deoxy-D-manno-octulosonate. J. Biol. Chem. 263, 5217-5223.

Guo, L., Lim, K. B., Gunn, J. S., Bainbridge, B., Darveau, R. P., Hackett, M., and Miller, S. I. (1997). Regulation of lipid A modifications by Salmonella typhimurium virulence genes phoP-phoQ. Science 276, 250-253.

Guo, L., Lim, K. B., Poduje, C. M., Daniel, M., Gunn, J. S., Hackett, M., and Miller, S. I. (1998). Lipid A acylation and bacterial resistance against vertebrate antimicrobial peptides. Cell 95 , 189-198.

Gupta, S. K., Masinick, S., Garrett,M., and Hazlett, L. D. (1997). Pseudomonas aeruginosa lipopolysaccharide binds galectin-3 and other human corneal epithelial proteins. Infect. Immun. 65 , 2747-2753.

Hajjar, A. M., Ernst, R. K., Tsai, J. H., Wilson, C. B., and Miller, S. I. (2002). Human toll-like receptor 4 recognizes host-specific LPS modifications. Nat. Immunol. 3, 354-359.

Hall-Stoodley, L., Costerton, J. W., and Stoodley, P. (2004). Bacterial biofilms: from the natural environment to infectious diseases. Nat. Rev. Microbiol. 2, 95-108.

Hancock, R. E., and Diamond, G. (2000). The role of cationic antimicrobial peptides in innate host defences. Trends Microbiol. 8, 402-410.

Hancock, R. E., Mutharia, L. M., Chan, L., Darveau, R. P., Speert, D. P., and Pier, G. B. (1983). Pseudomonas aeruginosa isolates from patients with cystic fibrosis: a class of serum-sensitive, nontypable strains deficient in lipopolysaccharide $\mathrm{O}$ side chains. Infect. Immun. 42, 170-177.

Hanlon, G. W. (2007). Bacteriophages: an appraisal of their role in the treatment of bacterial infections. Int. J. Antimicrob. Agents 30, 118-128.

Hauser, A. R. (2009). The type III secretion system of Pseudomonas aeruginosa: infection by injection. Nat. Rev. Microbiol. 7, 654-665.

Hayashi, T., Matsumoto, H., Ohnishi, M., Yokota, S., Shinomiya, T., Kageyama, M., and Terawaki, Y. (1994).
Cytotoxin-converting phages, phi CTX and PS21, are R pyocin-related phages. FEMS Microbiol. Lett. 122, 239-244.

Hoiby, N., Ciofu, O., and Bjarnsholt, T. (2010). Pseudomonas aeruginosa biofilms in cystic fibrosis. Future Microbiol. 5, 1663-1674.

Holloway, B.W., and Cooper, G.N. (1962). Lysogenic conversion in Pseudomona aeruginosa. J. Bacteriol. 84, 1321-1324.

Holmskov, U., Thiel, S., and Jensenius, J. C. (2003). Collectins and ficolins: humoral lectins of the innate immune defense. Annu. Rev. Immunol. 21 547-578.

Islam, S. T., Gold, A. C., Taylor, V. L., Anderson, E. M., Ford, R. C., and Lam, J. S. (2011). Dual conserved periplasmic loops possess essential charge characteristics that support a catch-and-release mechanism of $\mathrm{O}$-antigen polymerization by Wzy in Pseudomonas aeruginosa PAO1. J. Biol. Chem. 286, 20600-20605.

Islam, S. T., Taylor, V. L., Qi, M., and Lam, J.S. (2010). Membrane topology mapping of the O-antigen flippase (Wzx), polymerase (Wzy), and ligase (WaaL) from Pseudomonas aeruginosa $\mathrm{PAO} 1$ reveals novel domain architectures. mBio 1, e00189-10.

Ivanov, I. E., Kintz, E. N., Porter, L. A., Goldberg, J. B., Burnham, N. A., and Camesano, T. A. (2011). Relating the physical properties of Pseudomonas aeruginosa lipopolysaccharides to virulence by atomic force microscopy. J. Bacteriol. 193, 1259-1266.

Janeway, C. A. Jr., and Medzhitov, R. (2002). Innate immune recognition. Annu. Rev. Immunol. 20, 197-216.

Jarrell, K. F., and Kropinski, A. M. (1981a). Isolation and characterization of a bacteriophage specific for the lipopolysaccharide of rough derivatives of Pseudomonas aeruginosa strain PAO. J. Virol. 38, 529-538.

Jarrell, K. F., and Kropinski, A. M. (1981b). Pseudomonas aeruginosa bacteriophage phi PLS27-lipopolysaccharide interactions. J. Virol. 40, 411-420,

Jones, R. J., Roe, E. A., and Gupta, J. L. (1979). Controlled trials of a polyvalent Pseudomonas vaccine in burns. Lancet 314, 977-983.

Kadurugamuwa, J. L., Clarke, A. J., and Beveridge, T.J. (1993a). Surface action of gentamicin on Pseudomonas aeruginosa. J. Bacteriol. 175, 5798-5805.

Kadurugamuwa, J. L., Lam, J. S., and Beveridge, T. J. (1993b). Interaction of gentamicin with the A band and B band lipopolysaccharides of Pseudomonas aeruginosa and its possible lethal effect. Antimicrob. Agents Chemother. 37, 715-721.

Kaluzny, K., Abeyrathne, P. D., and Lam, J. S. (2007). Coexistence of two distinct versions of $\mathrm{O}$-antigen polymerase, Wzy-alpha and Wzy-beta, in Pseudomonas aeruginosa serogroup $\mathrm{O} 2$ and their contributions to cell surface diversity. J. Bacteriol. 189, 4141-4152.

Kidd, T. J., Grimwood, K., Ramsay, K. A., Rainey, P. B., and Bell, S. C. (2011). Comparison of three molecular techniques for typing Pseudomonas aeruginosa isolates in sputum samples from patients with cystic fibrosis. J. Clin. Microbiol. 49, 263-268.

King, J. D., Kocincova, D., Westman, E. L., and Lam, J. S. (2009). Review: lipopolysaccharide biosynthesis in Pseudomonas aeruginosa. Innate Immun. 15, 261-312.

King, J. D., Vinogradov, E., Tran, V., and Lam, J. S. (2010). Biosynthesis of uronamide sugars in Pseudomonas aeruginosa $\mathrm{O} 6$ and Escherichia coli O121 O-Antigens. Environ. Microbiol. 12, 1531-1544.

Kintz, E., Scarff, J. M., Digiandomenico, A., and Goldberg, J. B. (2008). Lipopolysaccharide $\mathrm{O}$-antigen chain length regulation in Pseudomonas aeruginosa serogroup O11 strain PA103. J. Bacteriol. 190, 2709-2716.

Kishore, U., Wang, J.-Y., Hoppe, H.-J., and Reid, K. B. M. (1996). The (-helical neck region of human lung surfactant protein $\mathrm{D}$ is essential for the binding of the carbohydrate recognition domains to lipopolysaccharides and phospholipids. Biophys. J. 318, 505-511.

Klausen, M., Heydorn, A., Ragas, P., Lambertsen, L., Aaes-Jørgensen, A., Molin, S., and Tolker-Nielsen, T. (2003). Biofilm formation by Pseudomonas aeruginosa wild type, flagella and type IV pili mutants. Mol. Microbiol. 48, 1511-1524.

Kneidinger, B., O'riordan, K., Li, J., Brisson, J. -R., Lee, J. C., and Lam, J. S. (2003). Three highly conserved proteins catalyze the conversion of UDP$\mathrm{N}$-acetyl-D-glucosamine to precursors for the biosynthesis of O-Antigen in Pseudomonas aeruginosa $\mathrm{O} 11$ and capsule in Staphylococcus aureus Type 5.J. Biol. Chem. 278, 3615-3627.

Knirel, Y. A., Bystrova, O. V., Kocharova, N. A., Zahringer, U., and Pier, G. B. (2006). Conserved and variable structural features in the lipopolysaccharide of Pseudomonas aeruginosa. J. Endotoxin. Res. 12, 324-336.

Kocharova, N. A., Knirel' Iu, A., Kochetkov, N. K., and Stanislavskii, E. S. (1988). Characteristics of rhamnan isolated from preparations of Pseudomonas aeruginosa lipopolysaccharides. Bioorg. Khim. 14, 701-703.

Kocíncová, D., Hao, Y., Vinogradov, E., and Lam, J. S. (2011). Evidence that WapB is an 1,2 glucosyltransferase 
of Pseudomonas aeruginosa involved in LPS outer core biosynthesis. J. Bacteriol. 193, 2708-2716.

Kocíncová, D., and Lam, J. S. (2011). Structural diversity of core oligosaccharide domain of $P$. aeruginosa lipopolysaccharide. Biochemistry (Mosc.) (accepted).

Köhler, T., Curty, L. K., Barja, F., Van Delden, C., and Pechère, J. -C. (2000). Swarming of Pseudomonas aeruginosa is dependent on cell-to-cell signaling and requires flagella and pili. $J$. Bacteriol. 182, 5990-5996.

Köhler, T., Donner, V., and Van Delden, C. (2010). Lipopolysaccharide as shield and receptor for R-pyocin-mediated killing in Pseudomonas aeruginosa. J. Bacteriol. 192, 1921-1928.

Kooistra, O., Bedoux, G., Brecker, L., Lindner, B., Sanchez Carballo, P., Haras, D., and Zahringer, U. (2003). Structure of a highly phosphorylated lipopolysaccharide core in the Delta algC mutants derived from Pseudomonas aeruginosa wild-type strains PAO1 (serogroup O5) and PAC1R (serogroup O3). Carbohydr. Res. 338, 2667-2677.

Koval, S. F., and Meadow, P. M. (1977). The isolation and characterization of lipopolysaccharide-defective mutants of Pseudomonas aeruginosa PAC1. J. Gen. Microbiol. 98, 387-398.

Kresse, A. U., Dinesh, S. D., Larbig, K., and Römling, U. (2003). Impact of large chromosomal inversions on the adaptation and evolution of Pseudomonas aeruginosa chronically colonizing cystic fibrosis lungs. Mol. Microbiol. 47, 145-158.

Kropinski, A. M., Farinha, M. A., and Jansons, I. (1994). Nucleotide sequence of the Pseudomonas aeruginosa insertion sequence IS222: another member of the IS3 family. Plasmid 31, 222-228.

Kulshin, V. A., Zahringer, U., Lindner, B., Jager, K. E., Dmitriev, B. A., and Rietschel, E. T. (1991). Structural characterization of the lipid A component of Pseudomonas aeruginosa wild-type and rough mutant lipopolysaccharides. Eur. J. Biochem. 198, 697-704.

Kunkel, T.A., and Erie, D. A. (2005). DNA mismatch repair. Annu. Rev. Biochem. 74, 681-710.

Kuzio, J., and Kropinski, A. M. (1983). O-antigen conversion in Pseudomonas aeruginosa $\mathrm{PAO} 1$ by bacteriophage D3 . J. Bacteriol. 155, 203-212.

Lam, J. S., Macdonald, L. A., and Lam, M. Y. (1987a).Production of monoclonal antibodies against serotype strains of Pseudomonas aeruginosa. Infect. Immun. 55, 2854-2856.

Lam, J. S., Macdonald, L. A., Lam, M. Y., Duchesne, L. G., and Southam, G. G. (1987b). Production and characterization of monoclonal antibodies against serotype strains of Pseudomonas aeruginosa. Infect. Immun. 55, 1051-1057.

Lam, M. Y., Mcgroarty, E. J., Kropinski, A. M., Macdonald, L. A., Pedersen, S. S., Hoiby, N., and Lam, J. S. (1989). Occurrence of a common lipopolysaccharide antigen in standard and clinical strains of Pseudomonas aeruginosa. J. Clin. Microbiol. 27, 962-967.

Lang, A. B., Rüdeberg, A., Schöni, M. H., Que, J. U., Fürer, E., and Schaad, U. B. (2004). Vaccination of cystic fibrosis patients against Pseudomonas aeruginosa reduces the proportion of patients infected and delays time to infection. Pediatr. Infect. Dis. J. 23, 504-510.

Lang, A. B., Schaad, U. B., Rüdeberg, A., Wedgwood, J., Que, J. U., Fürer, E., and Cryz, J. S. J. (1995). Effect of high-affinity anti-Pseudomonas aeruginosa lipopolysaccharide antibodies induced by immunization on the rate of Pseudomonas aeruginosa infection in patients with cystic fibrosis. J. Pediatr. 127, 711-717.

Lau, P. C. Y., Dutcher, J. R., Beveridge, T. J., and Lam, J. S. (2009a). Absolute quantitation of bacterial biofilm adhesion and viscoelasticity by microbead force spectroscopy. Biophys. J. 96, 2935-2948.

Lau, P. C. Y., Lindhout, T., Beveridge, T. J., Dutcher, J. R., and Lam, J. S. (2009b). Differential lipopolysaccharide core capping leads to quantitative and correlated modifications of mechanical and structural properties in Pseudomonas aeruginosa biofilms. J. Bacteriol. 191, 6618-6631.

Leclerc, J. E., Li, B., Payne, W. L., and Cebula, T. A. (1996). High mutation frequencies among Escherichia coli and Salmonella pathogens. Science 274, 1208-1211.

Lee, D. G., Urbach, J. M., Wu, G., Liberati, N. T., Feinbaum, R. L., Miyata, S., Diggins, L. T., He, J., Saucier, M., Deziel, E., Friedman, L., Li, L., Grills, G., Montgomery, K., Kucherlapati, R., Rahme, L. G., and Ausubel, F. M. (2006). Genomic analysis reveals that Pseudomonas aeruginosa virulence is combinatorial. Genome Biol. 7, R90.

Levine, A. M., Kurak, K. E., Bruno, M. D., Stark, J. M., Whitsett, J. A., and Korfhagen, T. R. (1998). Surfactant protein-A-deficient mice are susceptible to Pseudomonas aeruginosa infection. Am. J. Respir. Cell Mol. Biol. 19, 700-708.

Lightfoot, J., and Lam, J. S. (1991). Molecular cloning of genes involved with expression of A-band lipopolysaccharide, an antigenically conserved form, in Pseudomonas aeruginosa. J. Bacteriol. 173, 5624-5630.
Lightfoot, J., and Lam, J. S. (1993). Chromosomal mapping, expression and synthesis of lipopolysaccharide in Pseudomonas aeruginosa: a role for guanosine diphospho (GDP)-Dmannose. Mol. Microbiol. 8, 771-782.

Lindhout, T., Lau, P. C. Y., Brewer, D., and Lam, J. S. (2009). Truncation in the core oligosaccharide of lipopolysaccharide affects flagella-mediated motility in Pseudomonas aeruginosa PAO1 via modulation of cell surface attachment. Microbiology 155, 3449-3460.

Liu, P. V., Matsumoto, H., Kusama, H., and Bergan, T. O. M. (1983). Survey of heat-stable, major somatic antigens of Pseudomonas aeruginosa. Int. J. Syst. Bacteriol. 33, 256-264.

Liu, P. V., and Wang, S. (1990). Three new major somatic antigens of Pseudomonas aeruginosa. J. Clin. Microbiol. 28, 922-925.

Lyczak, J. B., Cannon, C. L., and Pier, G. B. (2000). Establishment of Pseudomona aeruginosa infection: lessons from a versatile opportunist. Microbes Infect. 2, 1051-1060.

Ma,S.,Selvaraj, U.,Ohman, D.E., Quarless, R., Hassett, D. J., and Wozniak, D. J. (1998). Phosphorylation-independent activity of the response regulators $\mathrm{AlgB}$ and $\mathrm{AlgR}$ in promoting alginate biosynthesis in mucoid Pseudomonas aeruginosa. J. Bacteriol. 180, 956-968.

Macfarlane, E. L., Kwasnicka, A., and Hancock, R. E. (2000). Role of Pseudomonas aeruginosa PhoP-phoQ in resistance to antimicrobial cationic peptides and aminoglycosides. Microbiology 146(Pt 10), 2543-2554.

Macintyre, S., Lucken, R., and Owen, P. (1986). Smooth lipopolysaccharide is the major protective antigen for mice in the surface extract from IATS serotype 6 contributing to the polyvalent Pseudomonas aeruginosa vaccine PEV. Infect. Immun. 52, 76-84.

Mariencheck, W. I., Savov, J., Dong, Q. Tino, M. J., and Wright, J. R. (1999). Surfactant protein A enhances alveolar macrophage phagocytosis of a live, mucoid strain of P. aeruginosa. Am. J. Physiol. 277, L777-L786.

Martin, N. L., and Beveridge, T. J. (1986). Gentamicin interaction with Pseudomonas aeruginosa cell envelope. Antimicrob. Agents Chemother. 29, 1079-1087.

Masoud, H., Altman, E., Richards, J. C. and Lam, J. S. (1994). General strategy for structural analysis of the oligosaccharide region of lipooligosaccharides. Structure of the oligosaccharide component of Pseudomonas aeruginosa IATS serotype 06 mutant R5 roughtype lipopolysaccharide. Biochemistry 33, 10568-10578.
Matewish, M. (2004). The Functional Role of Lipopolysaccharide in the Cell Envelope and Surface Proteins of Pseudomonas aeruginosa. Ph.D. thesis, University of Guelph, Guelph, ON, Canada.

Mcphee, J. B., Bains, M., Winsor, G., Lewenza, S., Kwasnicka, A., Brazas, M. D., Brinkman, F. S., and Hancock, R. E. (2006).Contribution of the PhoP-PhoQ and PmrA-PmrB two-component regulatory systems to $\mathrm{Mg} 2+$-induced gene regulation in Pseudomonas aeruginosa. J. Bacteriol. 188, 3995-4006.

Mcphee, J. B., Lewenza, S., and Hancock, R. E. (2003). Cationic antimicrobial peptides activate a two-component regulatory system, PmrA-PmrB, that regulates resistance to polymyxin $\mathrm{B}$ and cationic antimicrobial peptides in Pseudomonas aeruginosa. Mol. Microbiol. 50, 205-217.

Meadow, P. M., and Wells, P. L. (1978). Receptor sites for R-type pyocins and bacteriophage E79 in the Core Part of the lipopolysaccharide of Pseudomonas aeruginosa PAC1. J. Gen. Microbiol. 108, 339-343.

Mena, A., Smith, E. E., Burns, J. L., Speert, D. P., Moskowitz, S. M., Perez, J. L., and Oliver, A. (2008). Genetic adaptation of Pseudomonas aeruginosa to the airways of cystic fibrosis patients is catalyzed by hypermutation. J. Bacteriol. 190, 7910-7917.

Michel-Briand, Y., and Baysse, C. (2002). The pyocins of Pseudomonas aeruginosa. Biochimie 84, 499-510.

Miller, R. V., Pemberton, J. M., and Richards, K. E. (1974). F116, D3 and G101: temperate bacteriophages of Pseudomonas aeruginosa. Virology 59, 566-569.

Miller, S. I., Ernst, R. K., and Bader, M. W. (2005). LPS, TLR4 and infectious disease diversity. Nat. Rev. Microbiol. 3, 36-46.

Miller, W. L., Wenzel, C. Q., Daniels, C., Larocque, S., Brisson, J. R., and Lam, J. S. (2004). Biochemical characterization of WbpA, a UDP- $N$-acetylD-glucosamine 6-dehydrogenase involved in $\mathrm{O}$-antigen biosynthesis in Pseudomonas aeruginosa PAO1. J. Biol. Chem. 279, 37551-37558.

Mohan, S., Kelly, T. M., Eveland, S. S., Raetz, C. R., and Anderson, M. S. (1994). An Escherichia coligene (fabZ) encoding (3R)-hydroxymyristoyl acyl carrier protein dehydrase. Relation to fabA and suppression of mutations in lipid A biosynthesis. J. Biol. Chem. 269, 32896-32903.

Moskowitz, S. M., and Ernst, R. K. (2010). The role of Pseudomonas lipopolysaccharide in cystic fibrosis airway infection. Subcell. Biochem. 53, 241-253. 
Moskowitz, S. M., Ernst, R. K., and Miller, S. I. (2004). PmrAB, a two-component regulatory system of Pseudomonas aeruginosa that modulates resistance to cationic antimicrobial peptides and addition of aminoarabinose to lipid A. J. Bacteriol. 186, 575-579.

Mueller-Ortiz, S. L., Drouin, S. M., and Wetsel, R. A. (2004). The alternative activation pathway and complement component $\mathrm{C} 3$ are critical for a protective immune response against Pseudomonas aeruginosa in a murine model of pneumonia. Infect. Immun. 72, 2899-2906.

Mutharia, L. M., and Lam, J. S. (2007). "Antigen-antibody reactions," in Methods for General and Molecular Microbiology, 3rd Edn, eds C. A. Reddy, T. J. Beveridge, J. A. Breznak, G.A. Marzluf, T. M. Schmidt, and L. R. Snyder (Washington, DC: ASM Press), 138-167.

Newton, G. J., Daniels, C., Burrows, L. L., Kropinski, A. M., Clarke, A. J., and Lam, J. S. (2001). Three-componentmediated serotype conversion in Pseudomonas aeruginosa by bacteriophage D3. Mol. Microbiol. 39, 1237-1247.

Ni, M., Evans, D. J., Hawgood, S., Anders, E. M., Sack, R. A., and Fleiszig, S. M. J. (2005). Surfactant protein D is present in human tear fluid and the cornea and inhibits epithelial cell invasion by Pseudomonas aeruginosa. Infect. Immun. 73, 2147-2156.

O'toole, G. A., and Kolter, R. (1998). Flagellar and twitching motility are necessary for Pseudomonas aeruginosa biofilm development. Mol. Microbiol. 30, 295-304.

Oberhardt, M.A., Goldberg, J. B., Hogardt, M., and Papin, J.A. (2010). Metabolic network analysis of Pseudomonas aeruginosa during chronic cystic fibrosis lung infection. J. Bacteriol. 192, 5534-5548.

Ojeniyi, B., Lam, J. S., Hoiby, N., and Rosdahl, V. T. (1989). A comparison of the efficiency in serotyping of Pseudomonas aeruginosa from cystic fibrosis patients using monoclonal and polyclonal antibodies. APMIS 97, 631-636.

Ojeniyi, B., Wolz, C., Doring, G., Lam, J. S., Rosdahl, V. T., and Hoiby, N. (1990). Typing of polyagglutinable Pseudomonas aeruginosa isolates from cystic fibrosis patients. APMIS 98, 423-431.

Oliver, A., Baquero, F., and Blázquez, J. (2002). The mismatch repair system (mutS, mutL and uvrD genes) in Pseudomonas aeruginosa: molecular characterization of naturally occurring mutants. Mol. Microbiol. 43, 1641-1650.
Oliver, A., Cantón, R., Campo, P., Baquero, F., and Blázquez, J. (2000). High frequency of hypermutable Pseudomonas aeruginosa in cystic fibrosis lung infection. Science 288, 1251-1253.

Ovod, V., Rudolph, K., Knirel, Y., and Krohn, K. (1996). Immunochemical characterization of $O$ polysaccharides composing the alpha-D-rhamnose backbone of lipopolysaccharide of Pseudomonas syringae and classification of bacteria into serogroups $\mathrm{O} 1$ and $\mathrm{O} 2$ with monoclonal antibodies. J. Bacteriol. 178, 6459-6465.

Palsson-Mcdermott, E. M., and O'neill, L. A. (2004). Signal transduction by the lipopolysaccharide receptor, Toll-like receptor-4. Immunology 113, 153-162.

Pennington, J. E., Reynolds, H. Y., Wood, R. E., Robinson, R. A., and Levine, A. S. (1975). Use of a Pseudomonas aeruginosa vaccine in patients with acute leukemia and cystic fibrosis. Am. J. Med. 58, 629-636.

Pier, G. B., Grout, M., and Zaidi, T. S. (1997). Cystic fibrosis transmembrane conductance regulator is an epithelial cell receptor for clearance of Pseudomonas aeruginosa from the lung. Proc. Natl. Acad. Sci. U.S.A. 94, 12088-12093.

Pier, G. B., Grout, M., Zaidi, T. S., Olsen, J. C., Johnson, L. G., Yankaskas, J. R., and Goldberg, J. B. (1996). Role of mutant CFTR in hypersusceptibility of cystic fibrosis patients to lung infections. Science 271, 64-67.

Poon, K. K., Westman, E. L., Vinogradov, E., Jin, S., and Lam, J. S. (2008). Functional characterization of MigA and WapR: putative rhamnosyltransferases involved in outer core oligosaccharide biosynthesis of Pseudomonas aeruginosa. J. Bacteriol. 190, 1857-1865.

Postle, A. D., Mander, A., Reid, K. B. M., Wang, J. -Y., Wright, S. M., Moustaki, M., and Warner, J. O. (1999). Deficient hydrophilic lung surfactant proteins A and D with normal surfactant phospholipid molecular species in cystic fibrosis. Am. J. Respir. Cell Mol. Biol. 20, 90-98.

Raetz, C. R., and Whitfield, C. (2002). Lipopolysaccharide endotoxins. Annu. Rev. Biochem. 71, 635-700.

Raymond, C. K., Sims, E. H., Kas, A., Spencer, D. H., Kutyavin, T. V., Ivey, R. G., Zhou, Y., Kaul, R., Clendenning, J. B., and Olson, M. V. (2002). Genetic variation at the $\mathrm{O}$-antigen biosynthetic locus in Pseudomonas aeruginosa. J. Bacteriol. 184, 3614-3622.

Restrepo, C. I., Dong, Q., Savov, J., Mariencheck, W. I., and Wright, J. R. (1999). Surfactant protein D stimulates phagocytosis of Pseudomonas aeruginosa by alveolar macrophages.
Am. J. Respir. Cell Mol. Biol. 21, 576-585.

Rivera, M., Bryan, L. E., Hancock, R. E., and Mcgroarty, E. J. (1988) Heterogeneity of lipopolysaccharides from Pseudomonas aeruginosa: analysis of lipopolysaccharide chain length J. Bacteriol. 170, 512-521.

Rivera, M., Chivers, T. R., Lam, J. S., and Mcgroarty, E. J. (1992). Common antigen lipopolysaccharide from Pseudomonas aeruginosa AK1401 as a receptor for bacteriophage A7. J. Bacteriol. 174, 2407-2411.

Robbins, P. W., Keller, J. M., Wright, A., and Bernstein, R. L. (1965). Enzymatic and kinetic studies on the mechanism of O-Antigen conversion by bacteriophage epsilon-15. J. Biol. Chem. 240, 384-390.

Robertson, D. M., Petroll, W. M., Jester, J. V., and Cavanagh, H. D. (2007). Current concepts: contact lens related Pseudomonas keratitis. Cont. Lens Anterior Eye 30, 94-107.

Rocchetta, H. L., Burrows, L. L., Pacan, J. C., and Lam, J. S. (1998a). Three rhamnosyltransferases responsible for assembly of the A-band D-rhamnan polysaccharide in Pseudomonas aeruginosa: a fourth transferase, $\mathrm{WbpL}$ is required for the initiation of both A-band and B-band lipopolysaccharide synthesis. Mol. Microbiol. 28 1103-1119.

Rocchetta, H. L., and Lam, J. S. (1997) Identification and functional characterization of an $\mathrm{ABC}$ transport system involved in polysaccharide export of A-band lipopolysaccharide in Pseudomonas aeruginosa. J. Bacteriol. 179, 4713-4724.

Rocchetta, H. L., Pacan, J. C., and Lam, J. S. (1998b). Synthesis of the A-band polysaccharide sugar D-rhamnose requires Rmd and WbpW: identification of multiple AlgA homologues, WbpW and ORF488, in Pseudomonas aeruginosa. Mol. Microbiol. 29, 1419-1434.

Roy, P. H., Tetu, S. G., Larouche, A. Elbourne, L., Tremblay, S., Ren, Q. Dodson, R., Harkins, D., Shay, R., Watkins, K., Mahamoud, Y., and Paulsen, I. T. (2010). Complete genome sequence of the multiresistant taxonomic outlier Pseudomonas aeruginosa PA7. PLoS ONE 5, e8842. doi: 10.1371/journal.pone.0008842

Sadovskaya, I., Brisson, J. R., Lam, J. S., Richards, J. C., and Altman, E. (1998). Structural elucidation of the lipopolysaccharide core regions of the wild-type strain PAO1 and O-chaindeficient mutant strains AK1401 and AK1012 from Pseudomonas aeruginosa serotype O5. Eur. J. Biochem. 255 673-684.
Sanchez Carballo, P. M., Rietschel, E. T Kosma, P., and Zahringer, U. (1999). Elucidation of the structure of an alanine-lacking core tetrasaccharide trisphosphate from the lipopolysaccharide of Pseudomonas aeruginosa mutant H4. Eur. J. Biochem. 261, 500-508.

Sawada, S., Kawamura, T., Masuho, Y., and Tomibe, K. (1985). A new common polysaccharide antigen of strains of Pseudomonas aeruginosa detected with a monoclonal antibody. J. Infect. Dis. 152, 1290-1299.

Schiller, N., Hackley, D., and Morrison, A. (1984). Isolation and characterization of serum-resistant strains of Pseudomonas aeruginosa derived from serum-sensitive parental strains. Curr. Microbiol. 10, 185-189.

Schiller, N. L., Hatch, R. A., and Joiner, K. A. (1989). Complement activation and C3 binding by serumsensitive and serum-resistant strains of Pseudomonas aeruginosa. Infect. Immun. 57, 1707-1713.

Schmidt, K.D., Tümmler, B., and Römling, U. (1996). Comparative genome mapping of Pseudomonas aeruginosa $\mathrm{PAO}$ with $P$. aeruginos $a \mathrm{C}$, which belongs to a major clone in cystic fibrosis patients and aquatic habitats. J. Bacteriol. 178 , 85-93.

Sedlak-Weinstein, E., Cripps, A. W., Kyd, J. M., and Foxwell, A. R. (2005). Pseudomonas aeruginosa: the potential to immunise against infection. Expert Opin. Biol. Ther. 5, 967-982.

Senchenkova, S. N., Huang, X., Laux, P., Knirel, Y. A., Shashkov, A. S., and Rudolph, K. (2002). Structures of the $O$-polysaccharide chains of the lipopolysaccharides of Xanthomonas campestris pv phaseoli var fuscans GSPB 271 and $X$. campestris pv malvacearum GSPB 1386 and GSPB 2388. Carbohydr. Res. 337, 1723-1728.

Silby, M. W., Cerdeno-Tarraga, A. M., Vernikos, G. S., Giddens, S. R., Jackson, R. W., Preston, G. M., Zhang, X. X., Moon, C. D., Gehrig, S. M., Godfrey, S. A., Knight, C. G., Malone, J. G., Robinson, Z., Spiers, A. J., Harris, S. Challis, G. L., Yaxley, A. M., Harris, D., Seeger, K., Murphy, L., Rutter, S., Squares, R., Quail, M. A., Saunders, E., Mavromatis, K., Brettin, T. S. Bentley, S. D., Hothersall, J., Stephens, E., Thomas, C. M., Parkhill, J., Levy, S B., Rainey, P. B., and Thomson, N. R. (2009). Genomic and genetic analyses of diversity and plant interactions of Pseudomonas fluorescens. Genome Biol. 10, R51.

Smith, E. E., Buckley, D. G., Wu, Z., Saenphimmachak, C., Hoffman, L. R., D'argenio, D. A., Miller, S. I., Ramsey, B. W., Speert, D. P., Moskowitz, S. 
M., Burns, J. L., Kaul, R., and Olson, M. V. (2006). Genetic adaptation by Pseudomonas aeruginosa to the airways of cystic fibrosis patients. Proc. Natl. Acad. Sci. U.S.A. 103, 8487-8492.

Speert, D. P., Campbell, M. L., Puterman, J., Govan, J., Doherty, C., Hoiby, N., Ojeniyi, B., Lam, J. S., Ogle, J. W., Johnson, Z., Paranchych, W., Sastry, P. A., Pitt, T. L., and Lawrence, L. (1994). A multicenter comparison of methods for typing strains of Pseudomonas aeruginosa predominantly from patients with cystic fibrosis. The International Pseudomonas aeruginosa Typing Study Group. J. Infect. Dis. 169, 134-142.

Spencer, D. H., Kas, A., Smith, E. E., Raymond, C. K., Sims, E. H., Hastings, M., Burns, J. L., Kaul, R., and Olson, M.V. (2003).Whole-genome sequence variation among multiple isolates of Pseudomonas aeruginosa. J. Bacteriol. 185, 1316-1325.

Stanislavsky, E. S., and Lam, J. S. (1997). Pseudomonas aeruginosa antigens as potential vaccines. FEMS Microbiol. Rev. 21, 243-277.

Stover, C. K., Pham, X. Q., Erwin, A. L., Mizoguchi, S. D., Warrener, P., Hickey, M. J., Brinkman, F. S., Hufnagle, W. O., Kowalik, D. J., Lagrou, M. Garber, R. L., Goltry, L., Tolentino, E., Westbrock-Wadman, S., Yuan, Y., Brody, L. L., Coulter, S. N., Folger, K. R., Kas, A., Larbig, K., Lim, R., Smith, K., Spencer, D., Wong, G. K., Wu, Z., Paulsen, I. T., Reizer, J., Saier, M. H., Hancock, R. E., Lory, S., and Olson, M. V. (2000). Complete genome sequence of Pseudomonas aeruginosa PAO1, an opportunistic pathogen. Nature 406, 959-964.

Takada, H., and Kotani, S. (1992). "Structure-function relationships of lipid A," in Bacterial Endotoxic Lipopolysaccharides, Vol. I, Molecular Biochemistry and Cellular Biology, eds D. C. Morrison and J. L. Ryan (Boca Raton. FL: CRC press), 107-134.

Temple, G. S., Ayling, P.D., and Wilkinson, S. G. (1986). Isolation and characterization of a lipopolysaccharide-specific bacteriophage of Pseudomonas aeruginosa. Microbios 45, 81-91.

To, T. (2006). Purification and Characterization of WapP of Pseudomonas aeruginosa, a Putative Lipopolysaccharide Kinase. M.Sc. thesis, University of Guelph, Guelph.
Trent, M. S. (2004). Biosynthesis, transport, and modification of lipid A. Biochem. Cell Biol. 82, 71-86.

Walker, S. G., and Beveridge, T. J. (1988). Amikacin disrupts the cell envelope of Pseudomonas aeruginosa ATCC 9027. Can. J. Microbiol. 34, 12-18.

Walsh, A. G., Matewish, M. J., Burrows, L. L., Monteiro, M. A., Perry, M. B., and Lam, J. S. (2000). Lipopolysaccharide core phosphates are required for viability and intrinsic drug resistance in Pseudomonas aeruginosa. Mol. Microbiol. 35, 718-727.

Wang, J., Lory, S., Ramphal, R., and Jin, S. (1996). Isolation and characterization of Pseudomonas aeruginosa genes inducible by respiratory mucus derived from cystic fibrosis patients. Mol. Microbiol. 22, 1005-1012.

Weisner, A. M., Chart, H., Bush, A., Davies, J.C., and Pitt, T.L. (2007). Detection of antibodies to Pseudomonas aeruginosa in serum and oral fluid from patients with cystic fibrosis. J. Med. Microbiol. 56, 670-674.

Wenzel, C. Q., Daniels, C., Keates, R. A., Brewer, D., and Lam, J. S. (2005). Evidence that WbpD is an $\mathrm{N}$-acetyltransferase belonging to the hexapeptide acyltransferase superfamily and an important protein for $\mathrm{O}$-antigen biosynthesis in Pseudomonas aeruginosa PAO1. Mol. Microbiol. 57, 1288-1303.

Westman, E. L., Mcnally, D. J., Charchoglyan, A., Brewer, D., Field, R. A., and Lam, J. S. (2009). Characterization of $\mathrm{WbpB}, \mathrm{WbpE}$, and $\mathrm{WbpD}$ and reconstitution of a pathway for the biosynthesis of UDP-2,3-diacetamido-2,3-dideoxyD-mannuronic acid in Pseudomonas aeruginosa. J. Biol. Chem. 284, 11854-11862.

Westman, E. L., Preston, A., Field, R. A., and Lam, J. S. (2008). Biosynthesis of a rare Di- $N$-Acetylated Sugar in the lipopolysaccharides of both Pseudomonas aeruginosa and Bordetella pertussis occurs via an identical scheme despite different gene clusters. J. Bacteriol. 190 6060-6069.

Whiteley, M., Lee, K. M., and Greenberg, E. P. (1999). Identification of genes controlled by quorum sensing in Pseudomonas aeruginosa. Proc. Natl. Acad. Sci. U.S.A. 96, 13904-13909.
Whitfield, C. (1995). Biosynthesis of lipopolysaccharide $\mathrm{O}$ antigens. Trends Microbiol. 3, 178-185.

Winn, A. M., and Wilkinson, S. G. (1998). The O7 antigen of Stenotrophomonas maltophilia is a linear D-rhamnan with a trisaccharide repeating unit that is also present in polymers for some Pseudomonas and Burkholderia species. FEMS Microbiol. Lett. 166, 57-61.

Winstanley, C., Langille, M. G., Fothergill, J.L., Kukavica-Ibrulj, I., Paradis-Bleau, C., Sanschagrin, F., Thomson, N. R. Winsor, G. L., Quail, M. A., Lennard, N., Bignell, A., Clarke, L., Seeger, K. Saunders, D., Harris, D., Parkhill, J. Hancock, R. E., Brinkman, F. S., and Levesque, R. C. (2009). Newly introduced genomic prophage islands are critical determinants of in vivo competitiveness in the Liverpool epidemic strain of Pseudomonas aeruginosa. Genome Res. 19, 12-23.

Wolfgang, M. C., Kulasekara, B. R. Liang, X., Boyd, D., Wu, K., Yang, Q. Miyada, C. G., and Lory, S. (2003) Conservation of genome content and virulence determinants among clinical and environmental isolates of Pseudomonas aeruginosa. Proc. Natl. Acad. Sci. U.S.A. 100, 8484-8489.

Wyckoff, T. J., Lin, S., Cotter, R. J., Dotson, G. D., and Raetz, C. R. (1998). Hydrocarbon rulers in UDP$\mathrm{N}$-acetylglucosamine acyltransferases. J. Biol. Chem. 273, 32369-32372.

Yang, H., Matewish, M., Loubens, I., Storey, D. G., Lam, J. S., and Jin, S. (2000). migA, a quorum-responsive gene of Pseudomonas aeruginosa, is highly expressed in the cystic fibrosis lung environment and modifies lowmolecular-mass lipopolysaccharide. Microbiology 146, 2509-2519.

Yokota, S., Hayashi, T., and Matsumoto, H. (1994). Identification of the lipopolysaccharide core region as the receptor site for a cytotoxin-converting phage phi CTX, of Pseudomonas aeruginosa. J. Bacteriol. 176, 5262-5269.

Yokota, S., Kaya, S., Sawada, S., Kawamura, T., Araki, Y., and Ito, E. (1987) Characterization of a polysaccharide component of lipopolysaccharide from Pseudomonas aeruginosa IID 1008 (ATCC 27584) as D-rhamnan. Eur. J. Biochem. 167, 203-209.

Zaidi, T. S., Lyczak, J., Preston, M., and Pier, G. B. (1999). Cystic fibrosis transmembrane conductance regulator-mediated corneal epithelial cell ingestion of Pseudomonas aeruginosa is a key component in the pathogenesis of experimental murine keratitis. Infect. Immun. 67, 1481-1492.

Zhao, X., and Lam, J. S. (2002). WaaP of Pseudomonas aeruginosa is a novel eukaryotic type protein-tyrosine kinase as well as a sugar kinase essential for the biosynthesis of core ipopolysaccharide. J. Biol. Chem. 277, 4722-4730

Zhao, X., Wenzel, C. Q., and Lam, J. S. (2002). Nonradiolabeling assay for WaaP, an essential sugar kinase involved in biosynthesis of core lipopolysaccharide of Pseudomonas aeruginosa. Antimicrob. Agents Chemother. 46, 2035-2037.

Zuercher, A. W., Horn, M. P., Que, J. U., Ruedeberg, A., Schoeni, M. H., Schaad, U. B., Marcus, P., and Lang, A. B. (2006). Antibody responses induced by long-term vaccination with an octovalent conjugate Pseudomonas aeruginosa vaccine in children with cystic fibrosis. FEMS Immunol. Med. Microbiol. 47, 302-308.

Conflict of Interest Statement: The authors declare that the research was conducted in the absence of any commercial or financial relationships that could be construed as a potential conflict of interest.

Received: 21 March 2011; paper pending published: 18 April 2011; accepted: 12 May 2011; published online: 01 June 2011. Citation: Lam JS, Taylor VL, Islam ST, Hao Y and Kocíncová D (2011) Genetic and functional diversity of Pseudomonas aeruginosa lipopolysaccharide. Front. Microbio. 2:118. doi: 10.3389/ fmicb. 2011.00118

This article was submitted to Frontiers in Cellular and Infection Microbiology, a specialty of Frontiers in Microbiology.

Copyright () 2011 Lam, Taylor, Islam, Hao and Kocincová. This is an openaccess article subject to a non-exclusive license between the authors and Frontier Media SA, which permits use, distribution and reproduction in other forums, provided the original authors and source are credited and other Frontiers conditions are complied with 